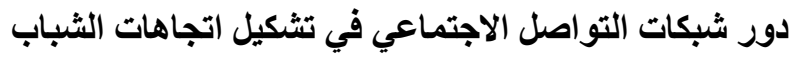

دور شبكات التواصل الاجتماعي في تثكيل اتجاهات الثباب نحو الأحداث الخارجية

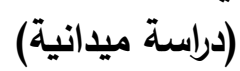

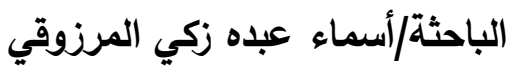

رسالة مقدمة لنيل درجة الماجستير في الآداب/ الإعلام/ الصحافة/ تكنولوجيا الفن الصحفي

$$
\text { إثراف }
$$

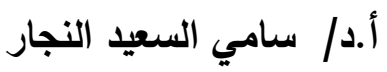

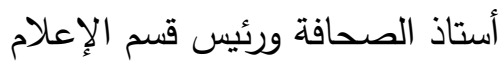

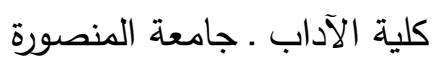

مقدمة: - مقام

تعد شبكات التواصل الاجتماعي نتيجة للتطورات المتلاحقة التي شهتتها شبكة الإنترنت في إنتاني

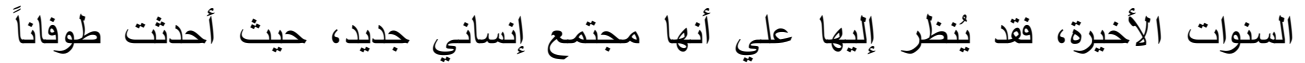

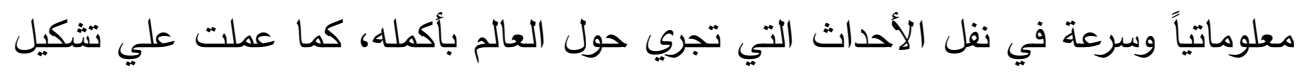

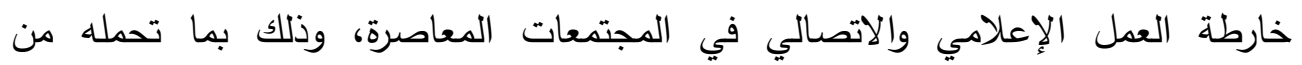
خصائص العملية الاتصالية وسرعة الوصول والتفاعل وانخفاض التكلفة. وإن قوة شبكات التواصل الاجتماعي لا تقتصر علي خاصية الإلية التفاعل، فقد أحدثت تغيراً نوعياً

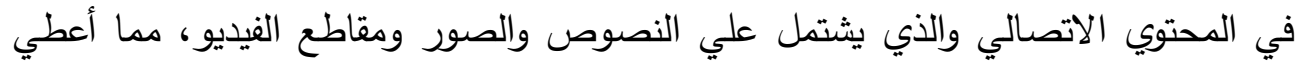

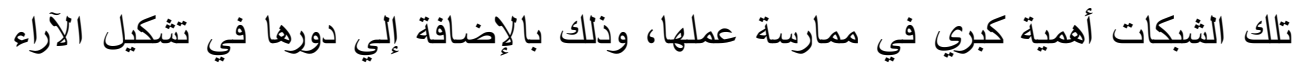

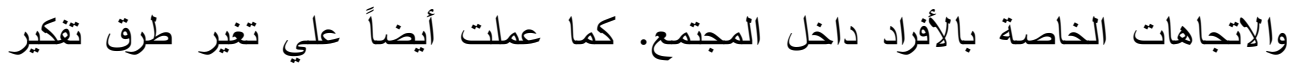

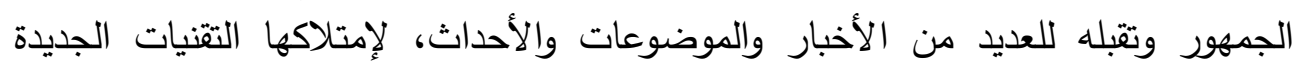

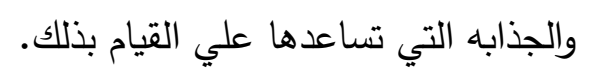
كما تعتبر شبكات التواصل الاجتماعي من أهم القنوات التيات التي تسهم بصورة كبيرة في تثكيل

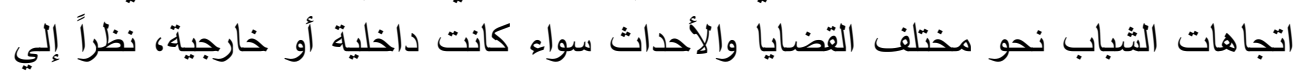

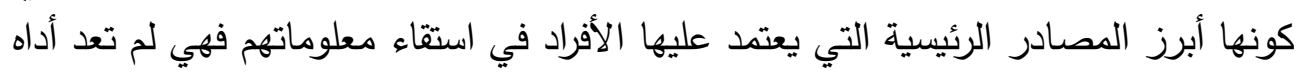

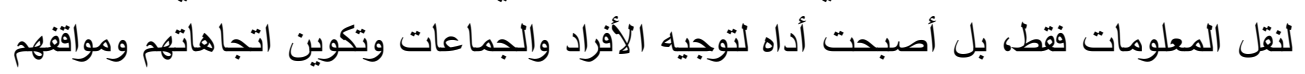

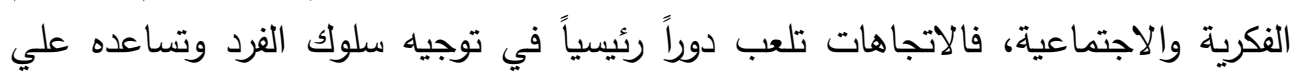
التكيف والتوافق الثخصي والاجتماعي وميوله اليختلفه.

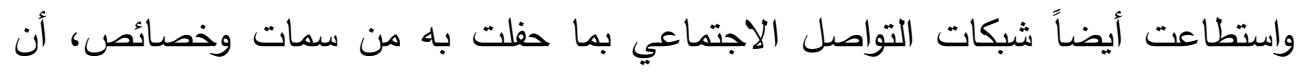

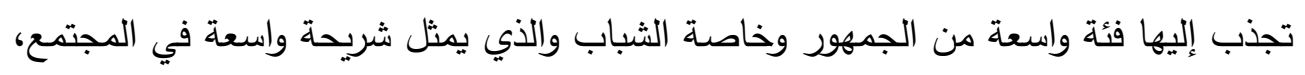


الباحثة/أسماء عبده زكي المرزوقي

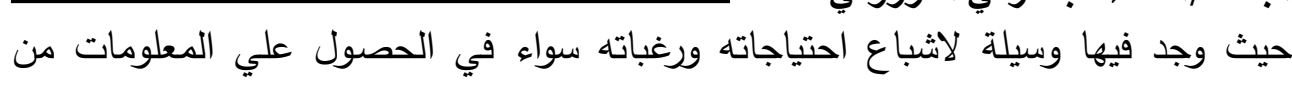
مصادر مختلفة أو تكوين علاقات اجتماعية مع أصداتئئه واتئه وعائلته.

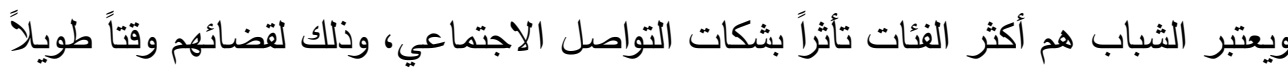

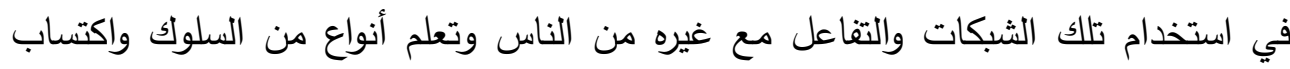
خبرات إيجابية من خلال هذا التفاعل، كما أن الثباب يُكون مدركاته المعرفية والأخلاقية

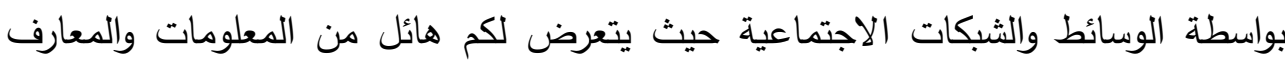

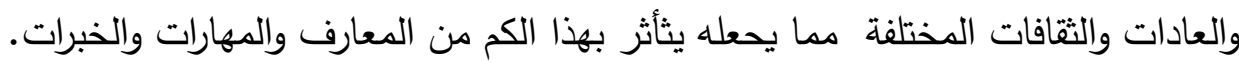

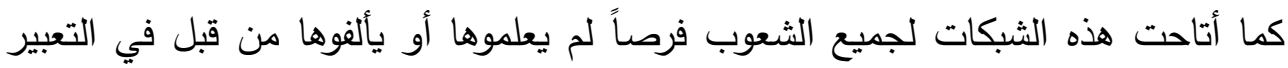

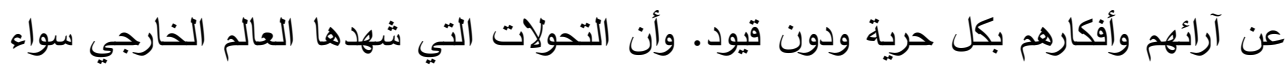

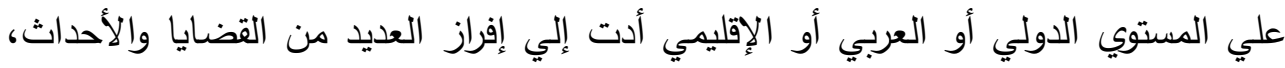

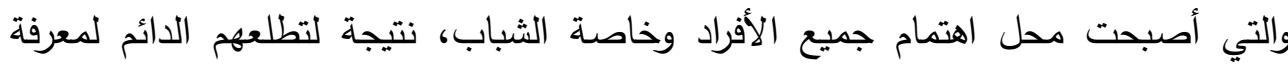
المزيد من المعلومات عن ما يحدث في العال العالم الخارجي.

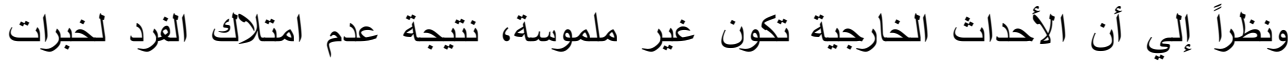

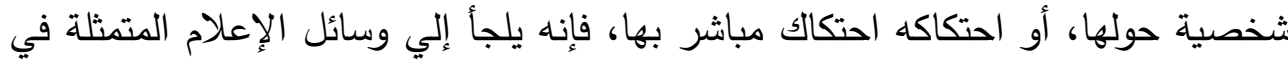

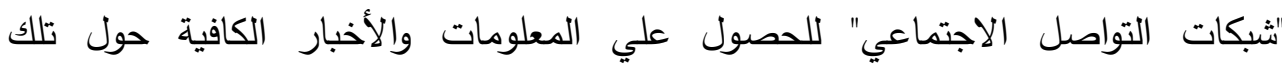

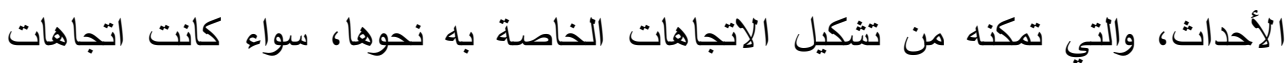
إيجابية أو اتجاهات سلبية. ومن هنا تظهر الحاجة إلي التعرف علي الدور الذي تقوم بله شبكابت التبات التواصل الاجتماعي لتثكيل اتجاهات الثباب نحو الأحداث الخارجية.

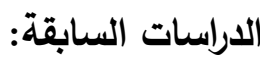

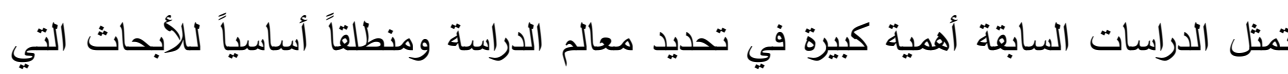

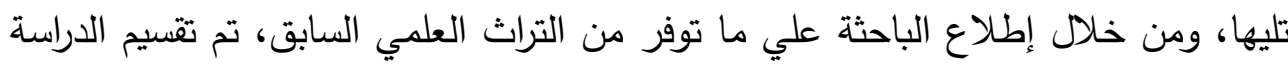

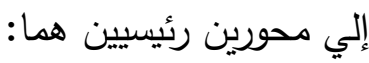

• المحور الأول: الاراسات التي تناولت علاقة الثباب بثبكات التواصل الاجتماعي.

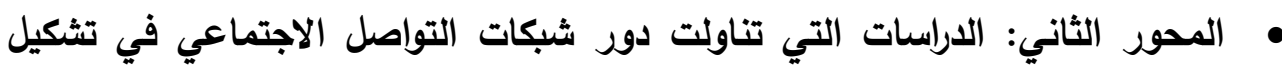

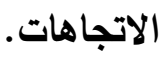

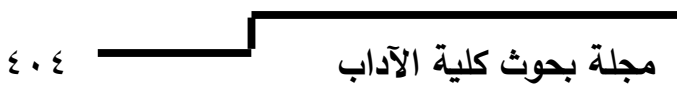




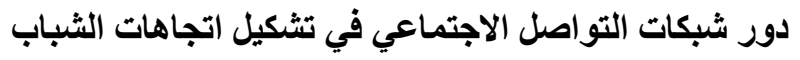

المحور الأول: الاراسات التي تناولت علاقة الثباب بشبكات التواصل الاجتماعي.

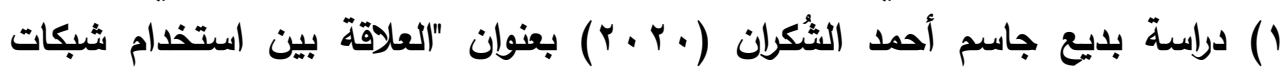

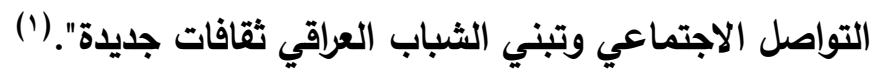

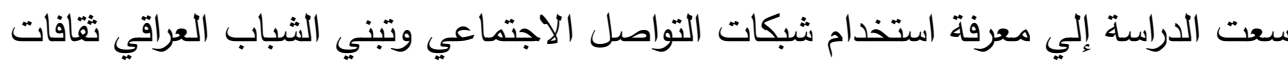

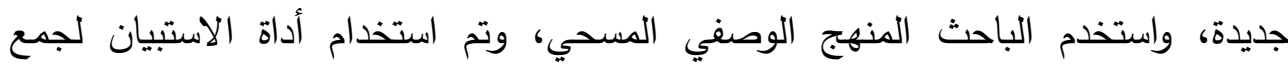

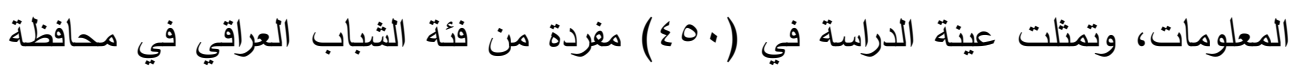

$$
\text { صلاح الدين. }
$$

وتوصلت الاراسة إلي: الدي:

- - أن الثباب العراقي يستخدم شبكات التواصل الاجتماعي من (r-ץ) ساعات يومياً.

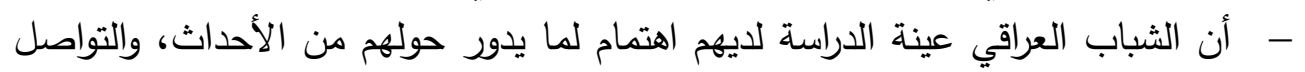

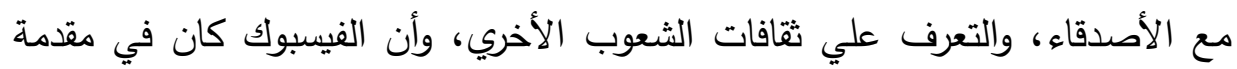
شبكات التواصل الاجتماعي الأخري.

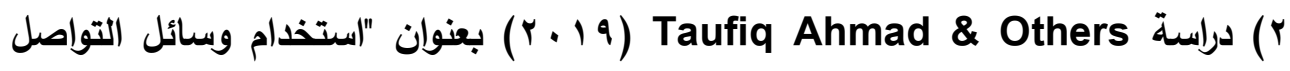

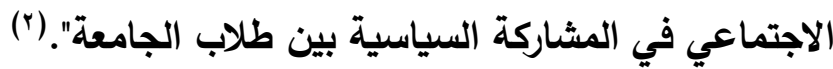

هدفت الدراسة إلي دراسة كيف تؤثر الأنشطة السياسية علي الإنترنت علي الفياعلي الفاعلية السياسية

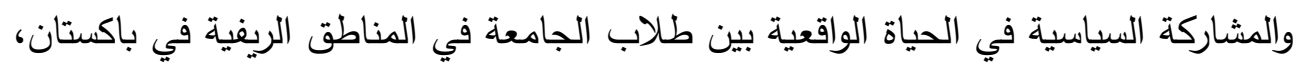

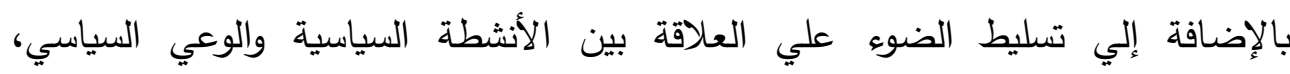

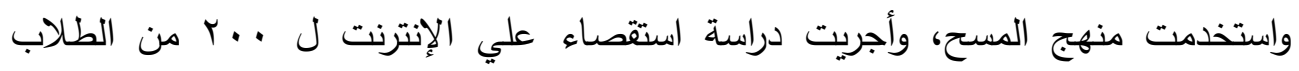
والخرجين من جامعة باكستان.

وتوصلت الاراسة إلي:

- - أن غالبية الطلاب يستخدمون وسائل الاتصال الاجتماعي للوعي السياسي والمعلومات. وتستند الفاعلية السياسية بشكل كبير علي المشاركة السياسية عبر الإنترنت.

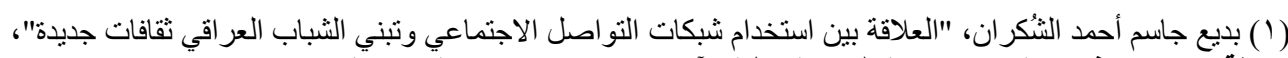

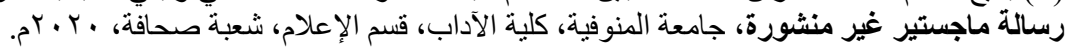

(1) Taufiq Ahmad, Aima Alvi and Muhammad Ittefaq, "The Use of Social Media on Political Participation Among University Students: An Analysis of Survey Results From Rural Pakistan", SAGE open, 2019. Availble at:

https://journals.sagepub.com/doi/full/10.1177/2158244019864484.

مجلة بحوث كلية الآداب

$\varepsilon \cdot 0$ 
الباحثة/أسماء عبده زكي المرزوقي - - مأن الأنشطة السياسية علي الإنترنت ترتبط ارتباطاً وثيقاً بالوعي السياسي والمشاركة السياسية خارج الإنترنت.

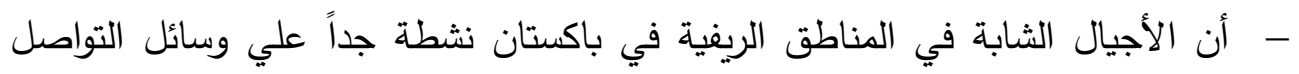

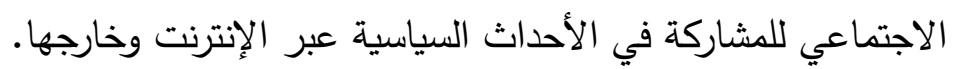

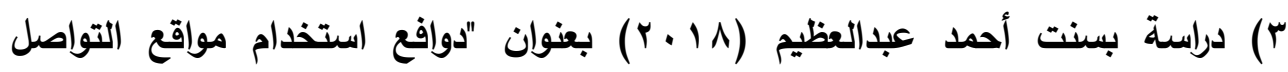

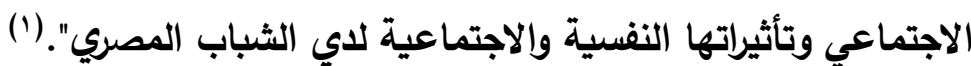

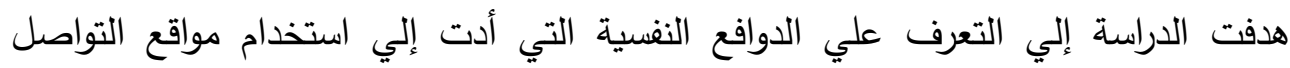

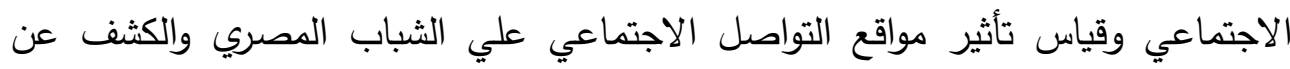

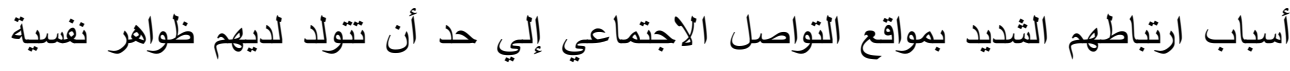

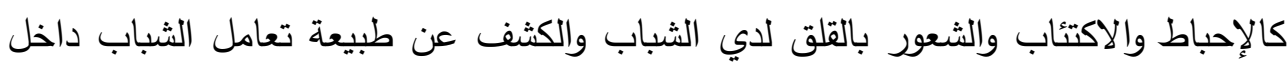

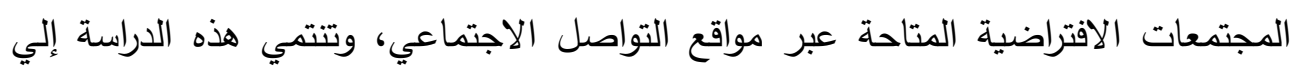

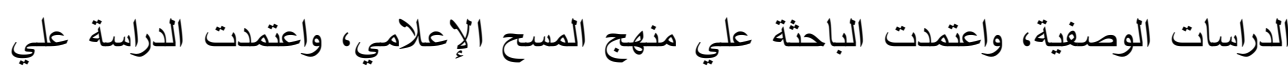

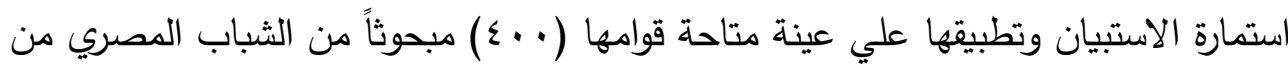

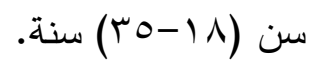

وتوصلت الدراسة إلي:

- - أن غالبية المبحوثين يمارسون أحياناً نشاط كتابة التعليقات علي ما يقرأونه أو يثاهدونه

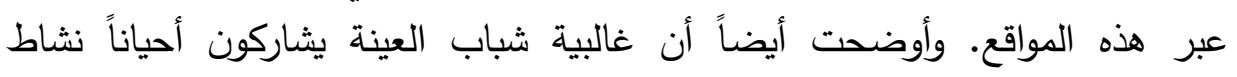

المشاركة بالتعليق

$$
\text { أو الإعجاب عند طرح أحد المستخدمين موضوعاً عن العاطفة. }
$$

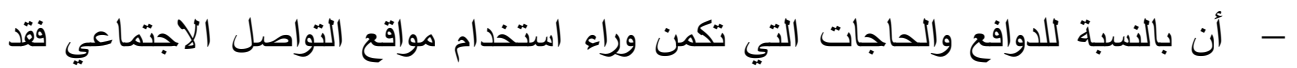

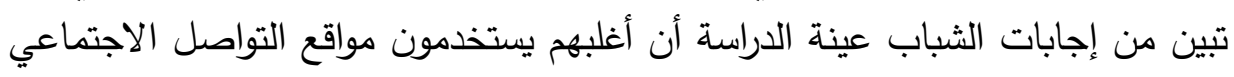

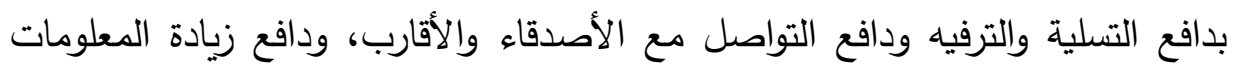

$$
\text { والمعارف. لدع }
$$

- - أن المبحوثين لديهم ثقة متوسطة بمواقع التواصل الاجتماعي، وذلك يدل علي صدق المحتوي المقدم لهم من خلال هذه المواقع.

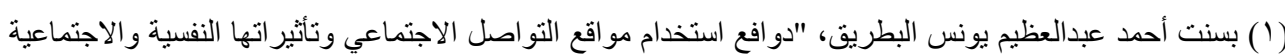

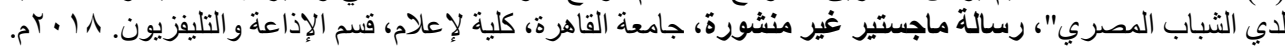


دور شبكات التو اصل الاجتماعي في تثكيل اتجاهات الثباب

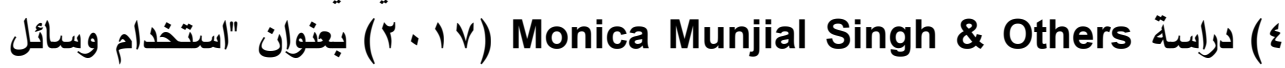

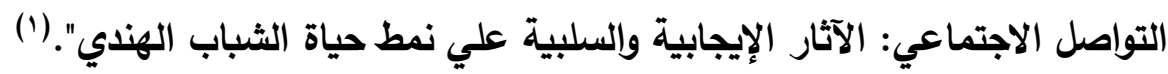

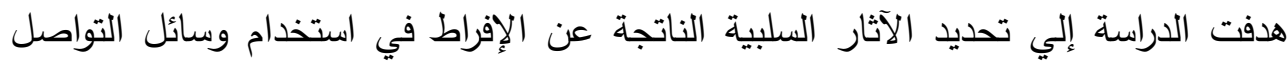

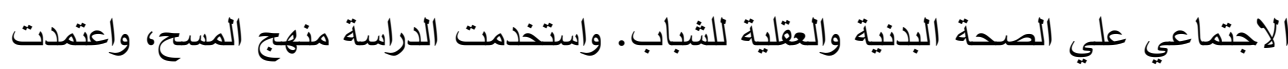

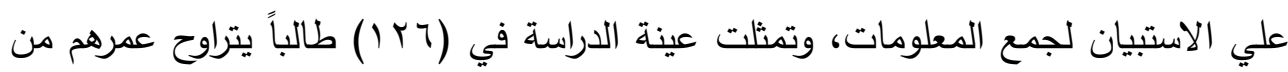

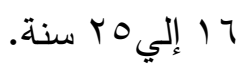
وتوصلت الداسة إلي:

- أن غالبية الثباب الذي تم اختيارهم يستخدمون وسائل التواصل الاجتماعي لغرض تصفح الموقع والدردشة والترفية.

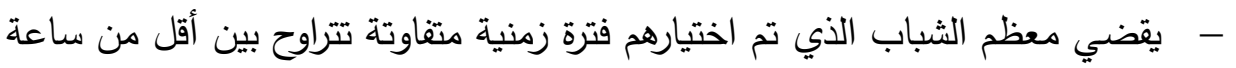
واحدة وأكثر من ه ساعات كل يوم علي وسائل التواصل الاجتماعي.

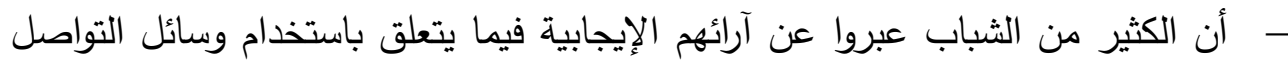

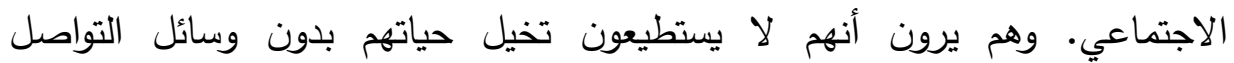

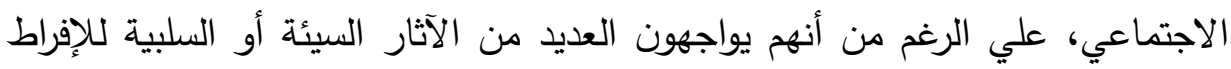
في استخدام وسائل التواصل الاجتم لنماعي.

المحور الثاني: الدراسات التي تناولت دور شبكات التواصل الاجتماعي في تثكيل الاتجاهات.

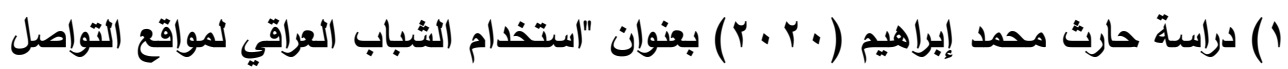

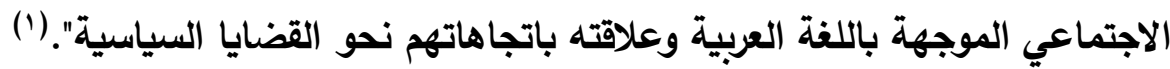

(1) Monica Munjial Singh, Mohammad Amiri \& Sherry Sabbarwal, "Social Media Usage: Positive and Negative Effects on the Life Style of Indian Youth", UCT JOURNAL OF SOCIAL SCIENCE AND HUMANITIES RESEARCH (04), 2017.

مجلة بحوث كلية الآداب

$\varepsilon \cdot V$ 
الباحثة/أسماء عبده زكي المرزوقي هدفت الدراسة إلي التعرف علي العلاقة بين استخدام الشباب لمواقع التواصل الاجتماعي واتجاهاتهم نحو القضايا السياسية، ووصف وتحليل كيف تؤثر هذه المواقع علي الثباب

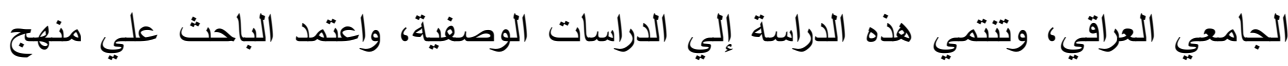

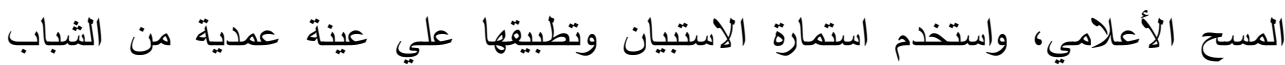
الجامعي العراقي من طلاب جامعة بغداد قوامها ( · م ع ) مفردة. وتوصلت الدراسة إلي: - - أن مواقع التواصل الاجتماعي تعد واحدة من الأسباب التي تساهم بثكل كبير في

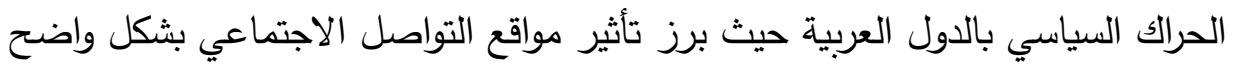
في الحياة السياسية للدول العربية من خلال ما يعرف "بأحداث الربيع العربي".

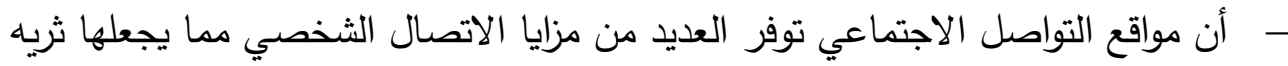

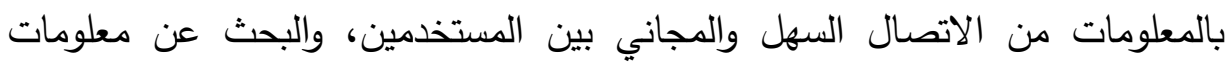
معينة بسهولة ويسر وبشكل مجاني بالإضافة إلي خصوصية الاتصال وإمكانية التعبير لئن عن الذات. r) دراسة أمل عبدالله العبدولي (19 ب r) بعنوان "دور شبكات التواصل الاجتماعي في

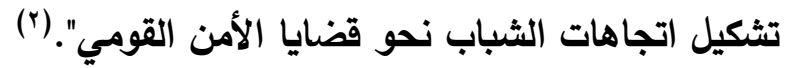

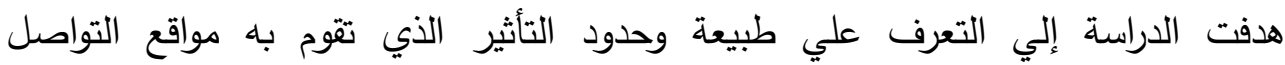
الاجتماعي في تثكيل اتجاهات الشباب الإماراتي نحو قضايا الأمن القومي. وتتتمي هذه بـانه الدراسة إلي الدراسات الوصفية، واعتمدت الدراسة علي منهج المسح، واستخدمت الباحثة

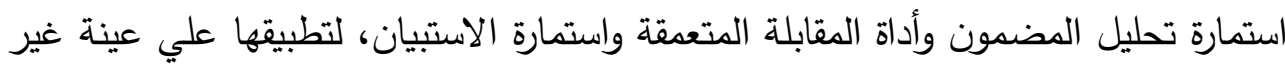
احتمالية عمدية من الشباب من طلبة جامعات الإمارات العربية المتحدة في الفئة العمرية

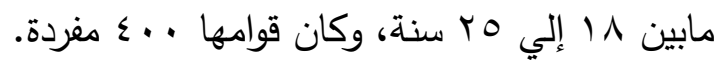
وتوصلت الدراسة إلي:

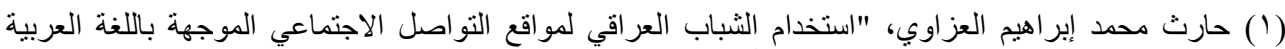

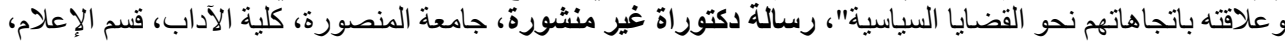

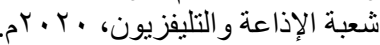

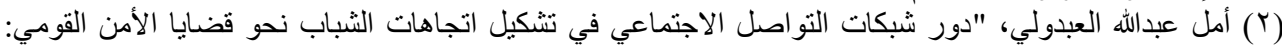

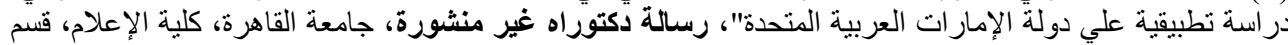

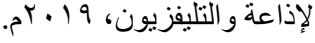

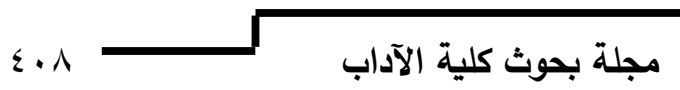




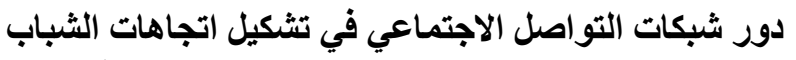

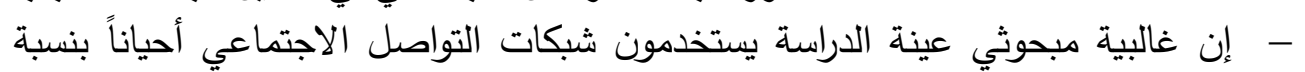

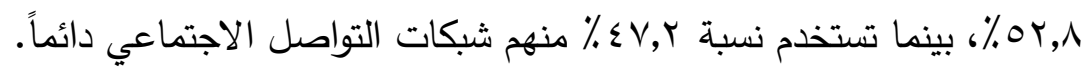

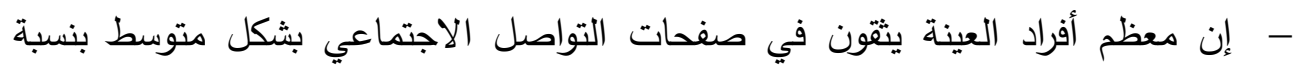
• . مستوي ثقة عينة الدراسة في صفحات مواقع التواصل الاجتماعي، خاصة في مناقئة فئسة الموضوعات الجادة.

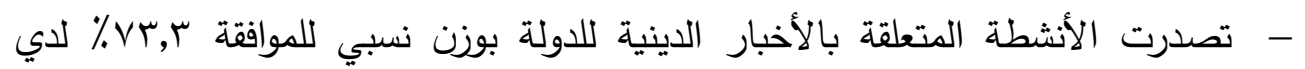

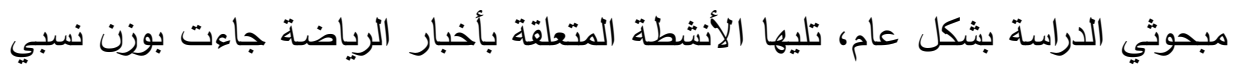

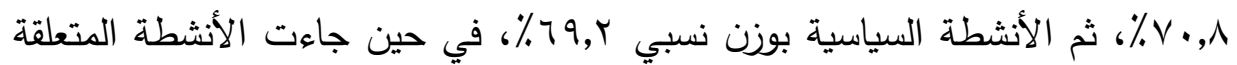

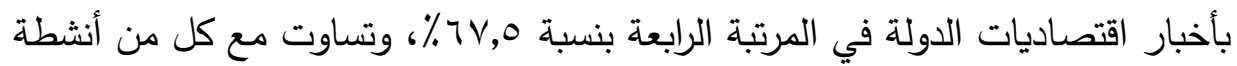

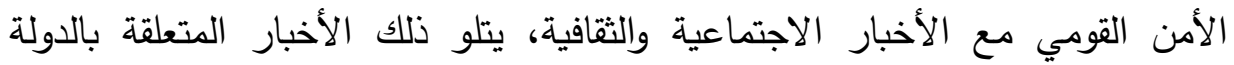

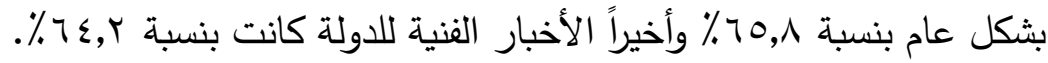

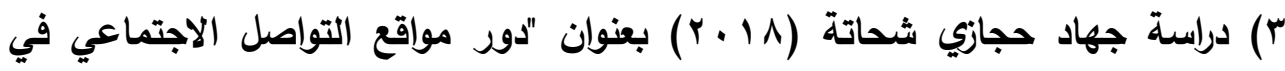

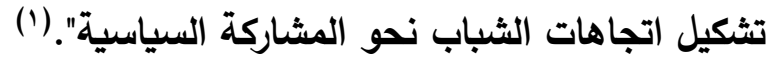
تحددت مشكلة الدراسة في محاولة معرفة دور مواقع التواصل الاجتماعي في تشكيل

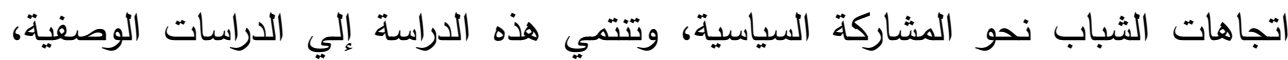
واعتمدت الدراسة علي منهج المسح الإعلامي بثقيه الكمي والكيفي، واستخدمت الباحثة استمارة الاستبيان وتطبيقها علي عينة عشوائية بسيطة قوامها ( • 1 ) مفردة من الثباب.

$$
\text { وتوصلت الدراسة إلي: }
$$

- - جاءت نسبة الاهتمام بالتعليق علي الآراء السياسية في شبكات التواصل الاجتماعي

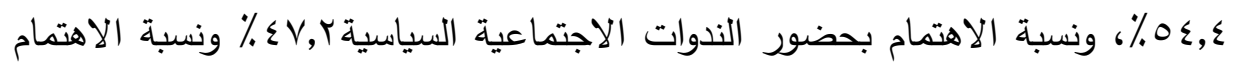

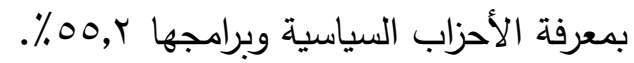


الباحثة/أسماء عبده زكي المرزوقي

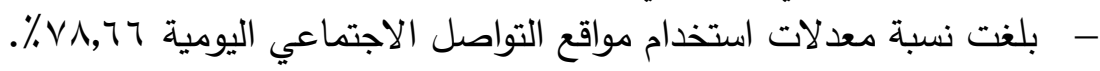

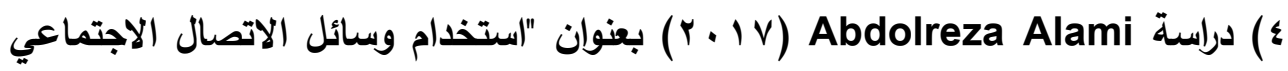

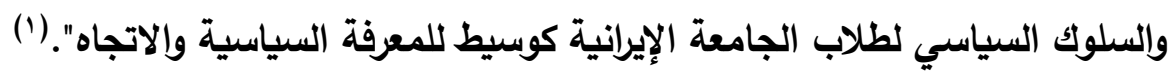

هدف البحث إلي دراسة العلاقات بين استخدام مواقع شبكات التواصل الاجتماعي محددة

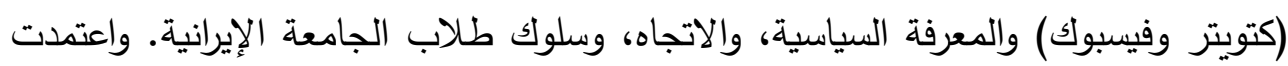

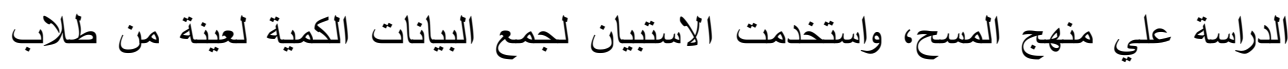

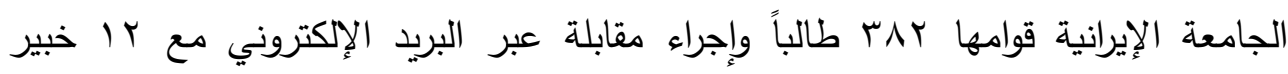

$$
\text { وإعلامي ومحاضراً. }
$$

- - وجود علاقة مباشرة وإيجابية بين مستوي استخدام شبكات التواصل الاجتماعي، والمعرفة السياسية، والاتجاه، والسلوك.

- - أن المجيبين استخدموا الفيسبوك أكثر من تويتر للمعلومات المحلية التي كانت مختلفة بشكل كبير، ولأخبار الوطنية اعتبر الفيسبوك كمصدر للمعلومات أكثر من تويتر ، وأخيراً بالنسبة للمعلومات الدولية استخدم المجيبين مرة أخري الفيسبوك أكثر من تويتر .

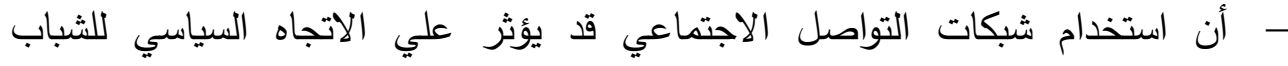
الإيراني، كما أن السمات الجوهرية لوسائل التواصل الاجتماعي تؤثر علي تغير وتشكيل

الاتجاه، سلوك الجمهور وخاصة الثباب في كل مكان.

التعليق علي الدراسات السابقة:

بعد اطلاع الباحثة علي بعض الدراسات السابقة والتي قد تم تقسيمها إلي محورين هما: دراسات تناولت علاقة الثباب بشبكات التواصل الاجتماعي، ودراسات تناولت دور شبكات التواصل الاجتماعي في تشكيل الاتجاهات، ويمكن التعليق علي الدراسات السابقة من خلاد

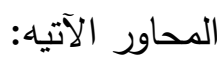

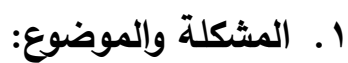

بالنسبة للمحور الأول الذي تتاول الدراسات الخاصة بعلاقة الثباب بشبكات التواصل

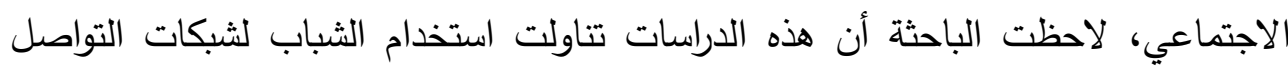

(1) Abdolreza alami, "Social Media Use and Political Behavior of Iranian University Students As Mediated By Political Knowledge And Attitude", PHD, University of Malaya, Faculty of Arts And Social Sciences, 2017. 


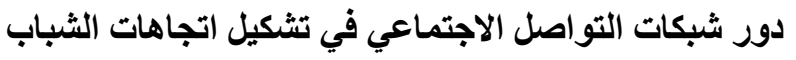

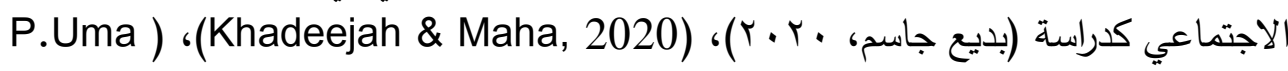

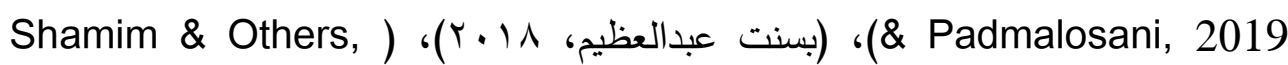

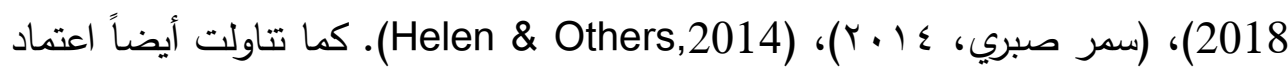

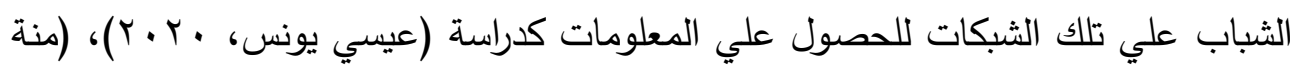

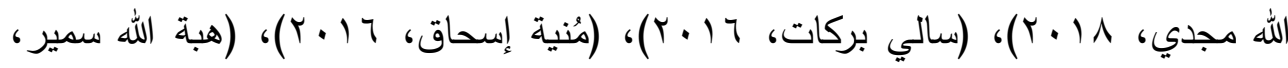

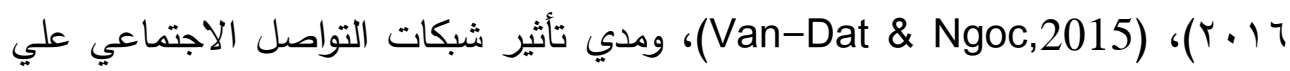

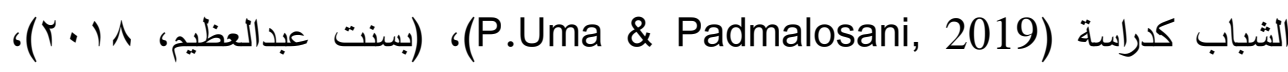

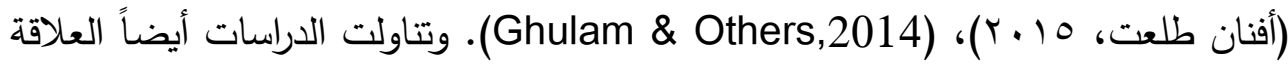

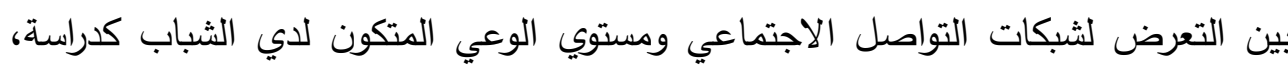

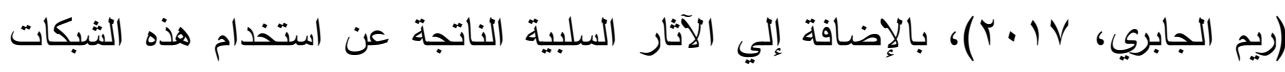
كدراسة (Monica \& Others 2017)

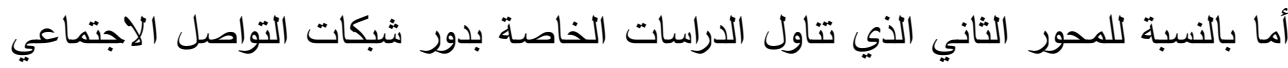

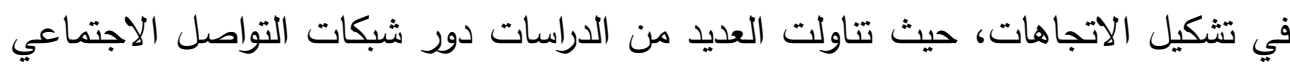

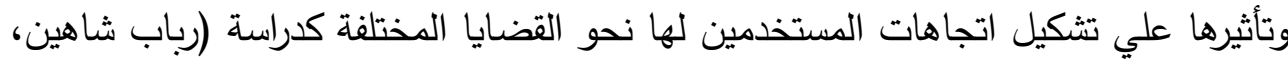

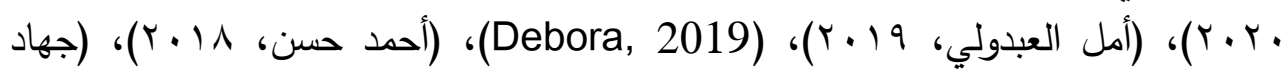

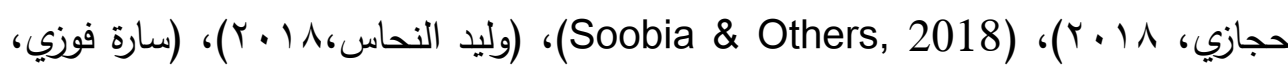
(Y.1Y

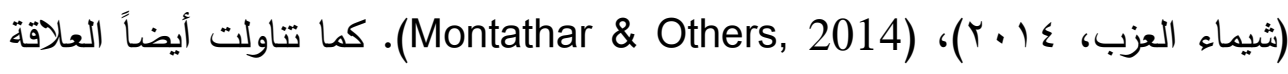

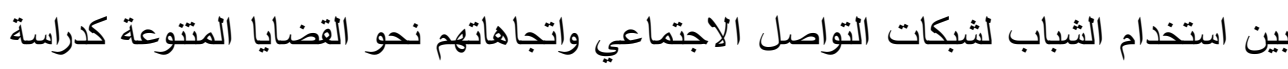

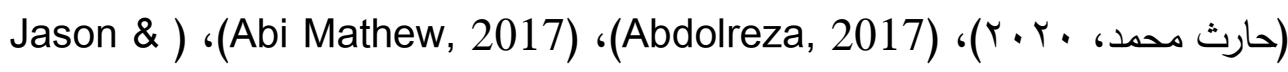

.(Others, 2016 لذا تناولت الدراسة الحالية دور شبكات التواصل الاجتماعي في تثكيل اتجاهات الثباب

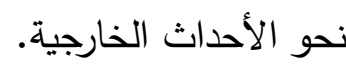

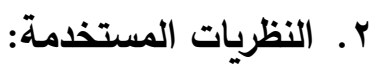

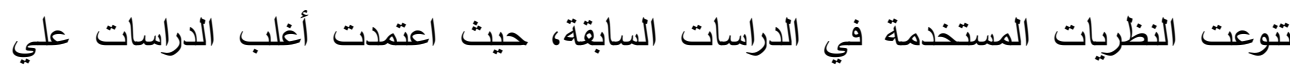

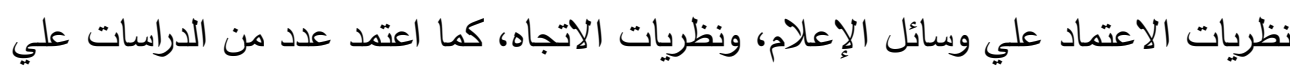

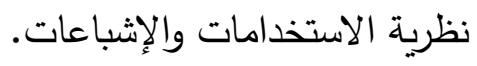


الباحثة/أسماء عبده زكي المرزوقي وقد أفاد هذا في تحديد النظرية التي تلائم الدراسة الحالية والتي تتمثل في نظرية الاعتماد علي وسائل الإعلام. r. المناهج المستخدمة وأدوات جمع البيانات: إعلات

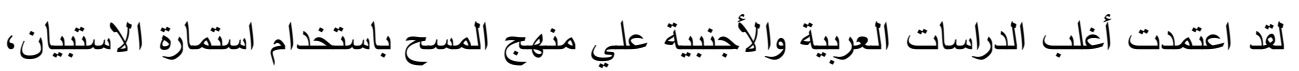

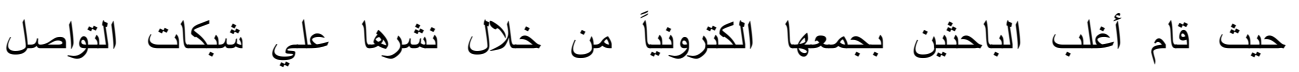
الاجتماعي، كما قامت عدة دراسات بتطبيق أداة تحليل المضمون، واعتمد بعض إنيات الباحثين علي استخدام أداة المقابلة. وقد أفاد هذا في تحديد المهنج المستخدم في الدراسة وهو منهج المسح، من خلال تطبيق استمارة الاستبيان علي عينة من الثباب.

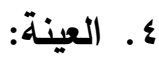

استعانت أغلب الدراسات السابقة باستخدام العينة العددية أو العشوائية في سحب مفردات الدراسة حتي تتتاسب مع طريقة توزيع الاستمارات عبر الشبكات الاجتماعية.

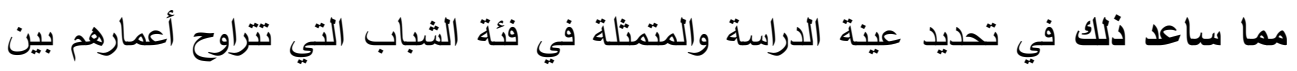

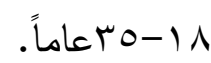

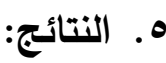
اتفقت نتائج أغلب الدراسات العربية والأحنبية في عدد من النقاط أهمها:

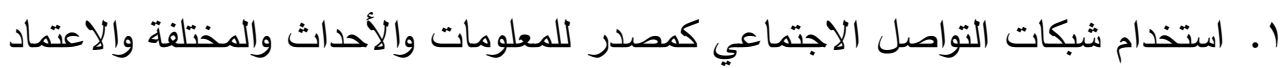

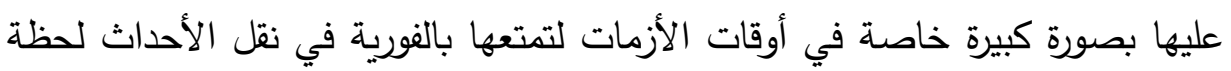

$$
\text { r. ارتفاع نسبة استخدام الثباب لشبكات التواصل الاجتماعي بشكل يومي. }
$$

r. تصدر الأحداث والقضايا السياسية، لمتابعتها من خلال شبكات التواصل الاجتماعي. ء. استخدام شبكات التواصل الاجتماعي كوسيلة للتواصل مع الأهل والأصدقاء والترفية

$$
\text { وقضاء وقت الفراغ. }
$$

ه. تأثير شبكات التواصل الاجتماعي علي الشباب سواء كان تأثيراً إيجابياً أو سلبياً. 7. تصدر استخدام الفيسبوك كأحد شبكات التواصل الاجتماعي الأكثر استخداماً.

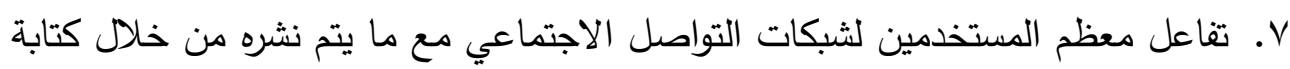

$$
\text { التعليقات أو الإعجاب أو المشاركة. }
$$


دور شبكات التو اصل الاجتماعي في تثكيل اتجاهات الثباب

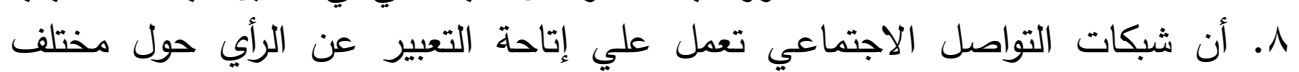

القضايا التي تتشر من خلالها.

مدي إفادة الباحثة من الدراسات السابقة:

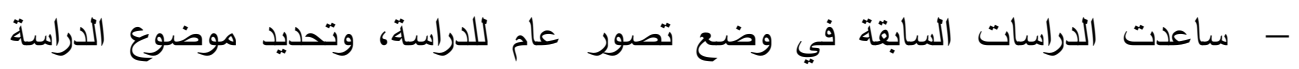
ومتغيراتها.

- - ساعدت الدراسات السابقة في تحديد الإطار المنهجي للدراسة من حيث نوع الدراسة، والمنهج المستخدم، والعينة، وأدوات جمع البيانات.

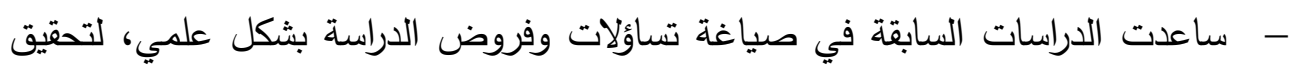
الأهداف التي تسعي إليها الدراسة.

- ماعدت الدراسات السابقة في تحديد النظرية التي تم استخدامها في الدراسة وهي نظرية الاعتماد علي وسائل الإعلام.

- - ساعدت الدراسات السابقة في مناقشة نتائج الدراسة الحالية ومقارنتها بنتائج الدراسات السابقة، مما يساعد علي معرفة الاختلاف والتشابه في النتائج وتفسيرها بشكل أعمق.

مشكلة الدراسة:

يتضح من الدراسات السابقة الخاصة بموضوع الدراسة إن شبكات التواصل الاجتماعي

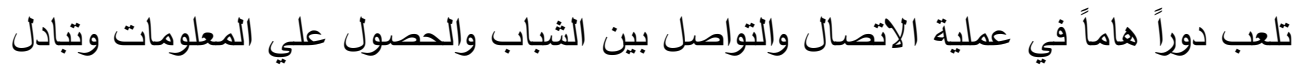

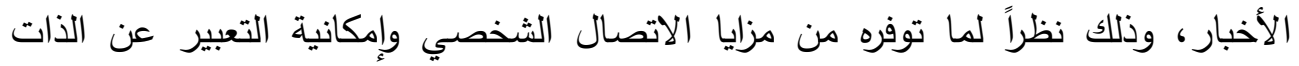
وسهولة الاستخدام وانخفاض التكلفة والسرعة والفورية في نقل الأحداث. كما أنها أصبحت الصدي من أهم العوامل المؤثرة في عملية تثكيل الاتجاهات. وذلك لقدرتها الكبيرة علي توفير كم

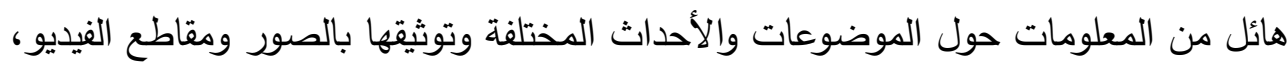

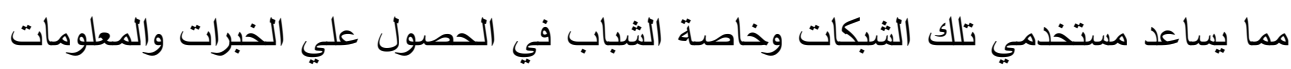

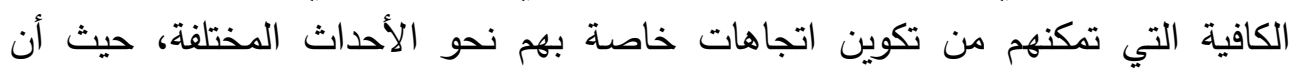

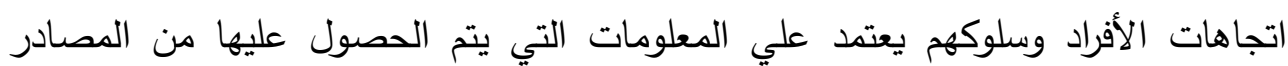
المتتوعة. ومن هنا تتحدد مشكلة الاراسة في التعرف علي دور شبكات التواصل الاجتماعي في تشكيل اتجاهات الثباب نحو الأحداث الخارجية. أهمية الاراسة: أولاً: الأهمية العلمية للدراسة: 


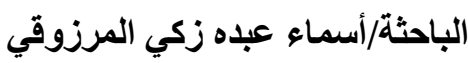

1. توضح الدراسة مدي تأثير شبكات التواصل الاجتماعي علي اتجاهات الثباب، وإنه لم

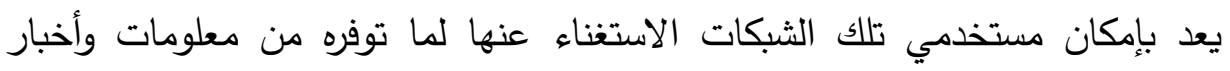

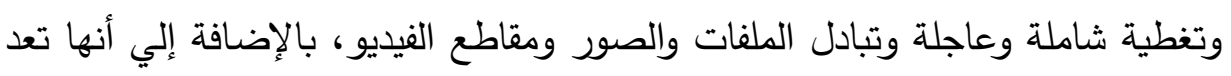

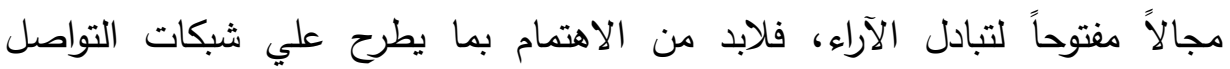

$$
\text { الاجتماعي من أحداث وقضايا. }
$$

r. رصد الدور الذي تمارسة شبكات التواصل الاجتماعي لتثكيل اتجاهات الثباب نحو

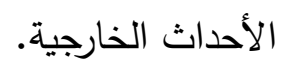

r. أكد كثير من الباحثين علي أهمية شبكات التواصل الاجتماعي وأنها أصبحت محور الأدراسات الإعلامية الجديدة.

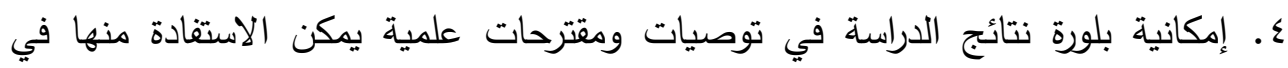
مجال الإعلام بصفة عامة، والدراسات الخاصة بشبكات التواصل الاجتماعي بصفة

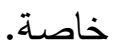

0. تساهم هذه الدراسة في إثراء الأدبيات العلمية ذات العلاقة بظاهرة شبكات التواصل

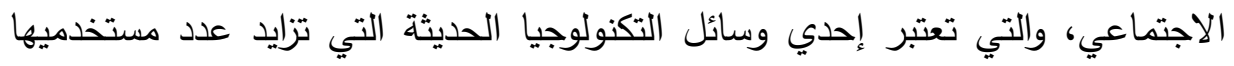

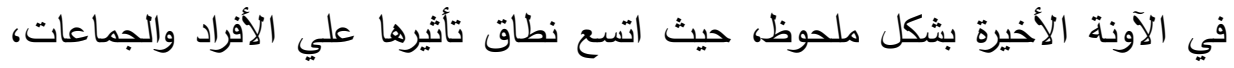

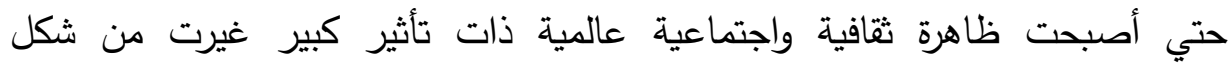
الاتصال واتجاهاته.

ثانياً: الأهمية التطبيقية للدراسة:

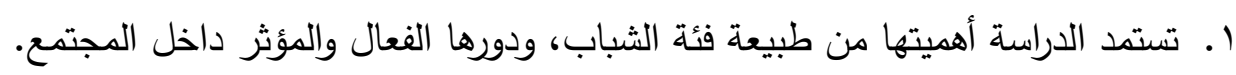

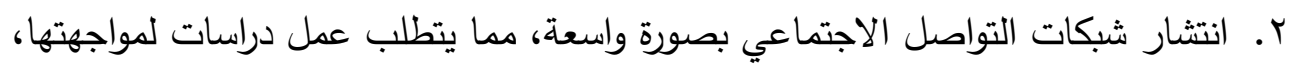

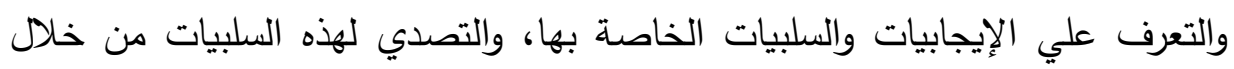

$$
\text { اقتراح الحل المناسب لها. }
$$

r. في ضوء ما سيتم التوصل إليه من نتائج يمكن وضع الخطط المناسبة لتوعية الثباب الثناب بالأحداث المختلفة وخاصة الأحداث الخارجية.

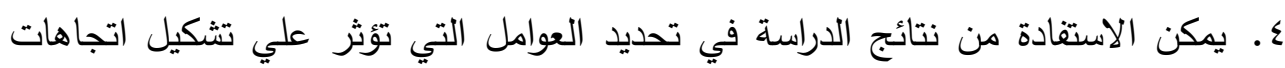

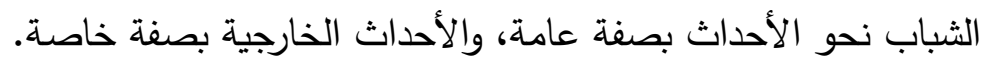

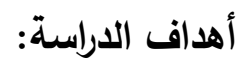


دور شبكات التو اصل الاجتماعي في تثكيل اتجاهات الثباب

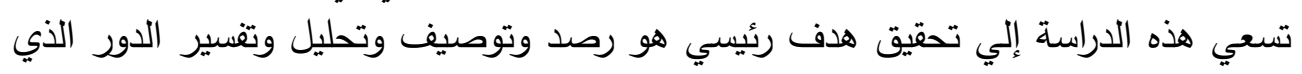

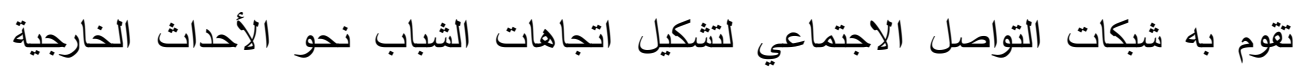

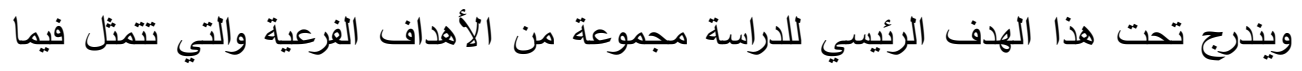
يلي: ا ـ التعرف علي مدي متابعة الثباب لثبكات التواصل الاجتماعي.

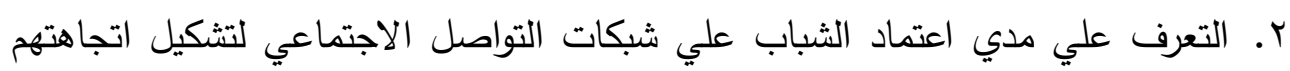

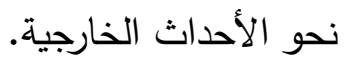
r. التعرف علي درجة متابعة الشباب للأحداث الخارجية علي شبكات التواصل الاجتماعي.

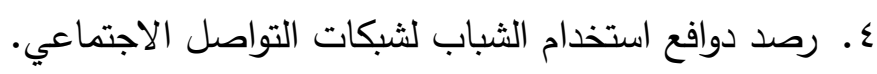

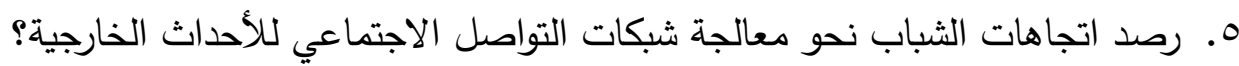

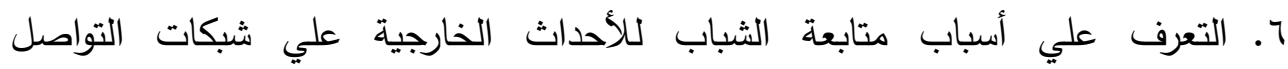

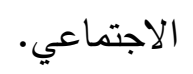

V. التعرف علي أبرز الأحداث الخارجية التي يتابعها الثباب علي شبكات التواصل

$$
\text { الاجتماعي. }
$$

^. رصد الآثار المعرفية والوجدانية والسلوكية الناتجة عن تعرض الثباب لثبكات التواصل

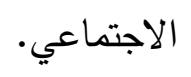

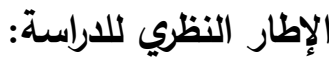

استندت الدراسة في إطارها النظري علي نظرية الاعتماد علي وسائل الإعلام، نظراً لما لإليا

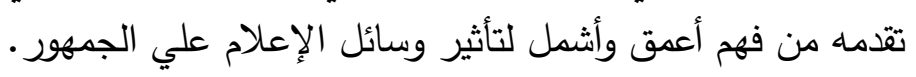

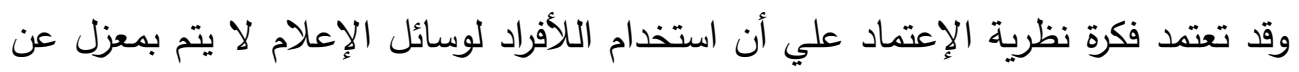

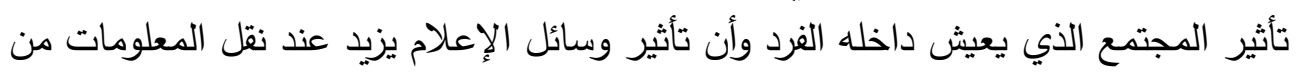

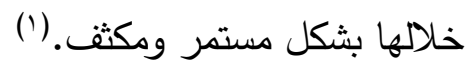

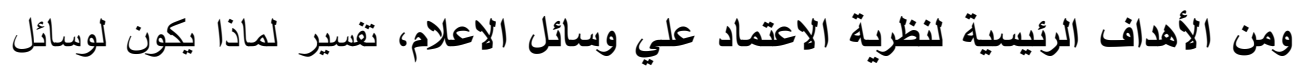

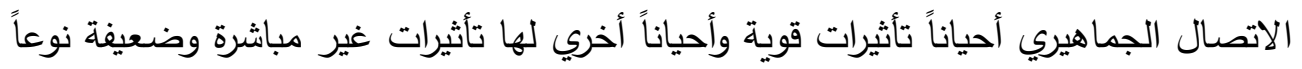




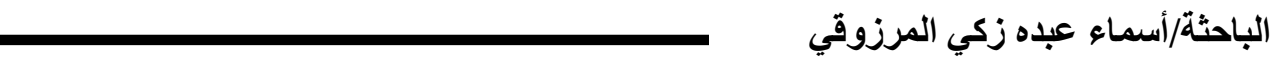
فروض نظرية الاعتماد علي وسائل الإعلام:

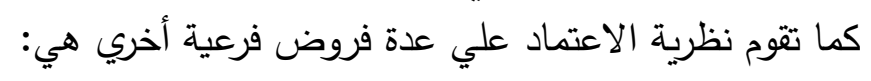

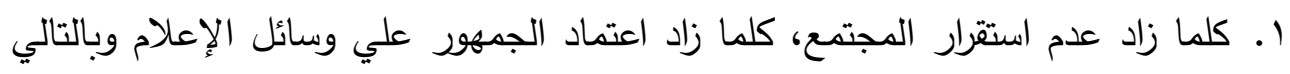

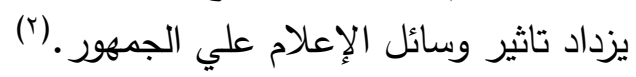

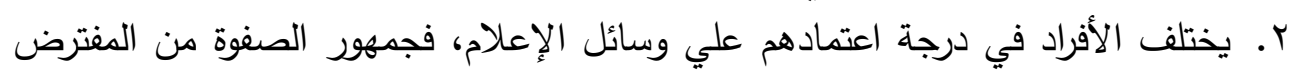
أن يكون لديهم مصادر للمعلومات متتوعة تجعلهم يتفاوتون في درجة اعتمادهم علي

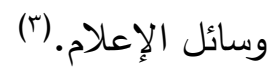
r. يعتبر نظام وسائل الإعلام جزء من النسق الإجتماعي للمجتمع، وأن هذا النظام لله

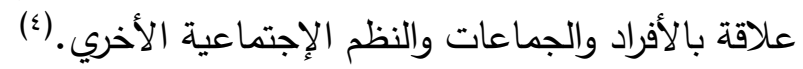

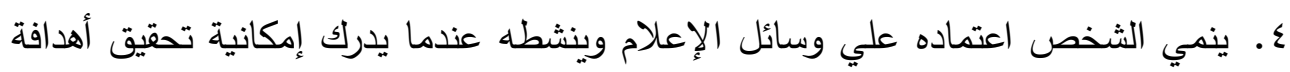

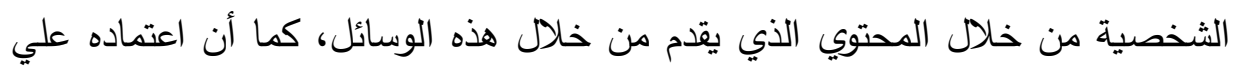

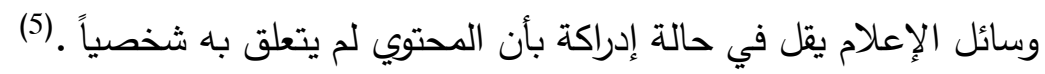

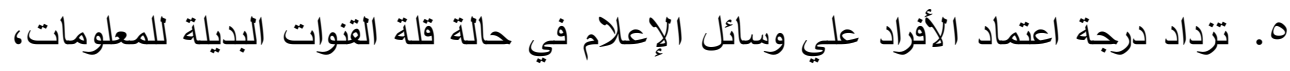

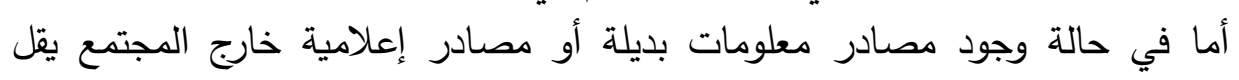

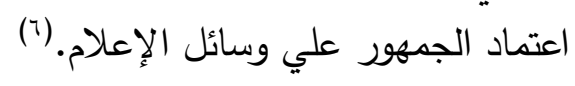
توظيف نظرية الاعتماد في إطار الاراسة الحالية: نظراً للاستخدام المتزايد لشبكات التواصل الاجتماعي من قبل الإن الثبل الثباب، واستخدامها كوسيلة للتواصل والحصول علي المعلومات حول الأخبار والأحداث المختلفة، فإن نظرية الاعتماد علي وسائل الإعلام تعد مدخلاً ملائماً للدراسة الحالية للأسباب التالية: - التعرف علي العلاقة بين الاعتماد علي شبكات التواصل الاجتماعي ومدي تأثيرها علي اتجاهات الثباب نحو الأحداث الخارجية.

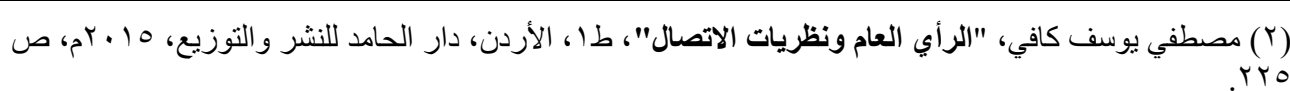

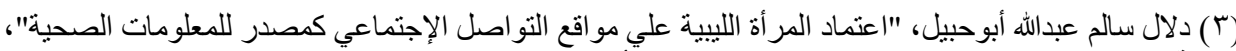

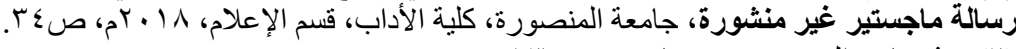

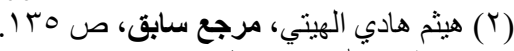

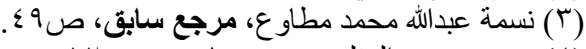

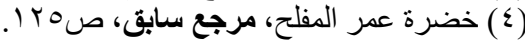


دور شبكات التو اصل الاجتماعي في تثكيل اتجاهات الثباب

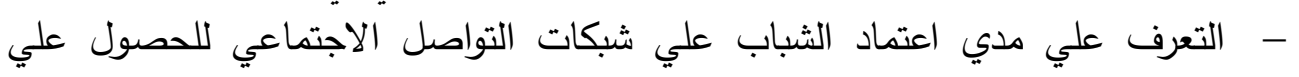
المعلومات حول الأحداث الخارجية.

- اعتماد الدراسة علي افتراض رئيسي للنظرية يري أن الاعتماد علية النية وسائل الإعلام ينتج

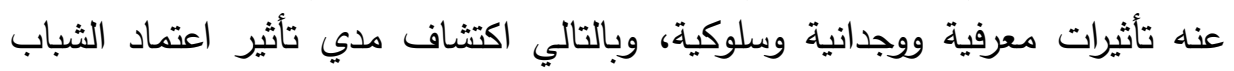

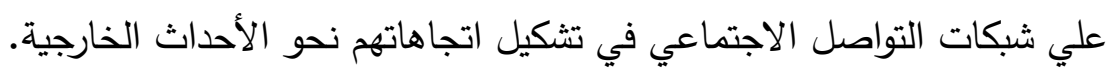

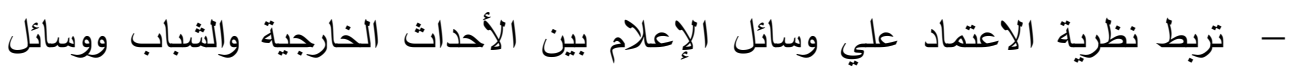

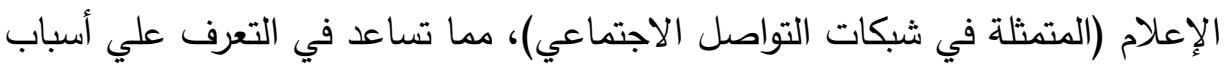

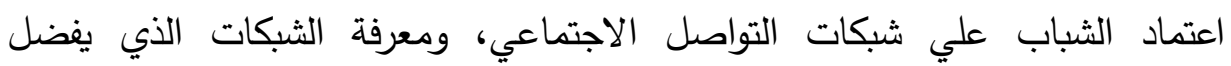
التعرض إليها. - تفيد هذه النظرية في دراسة تأثير المتغيرات الديموغرافية علي الاعتماد، وذلك وفقاً لأحد

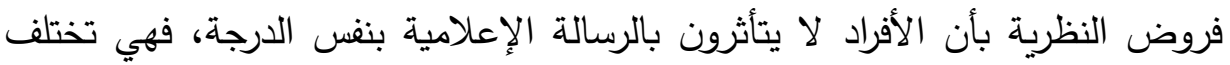

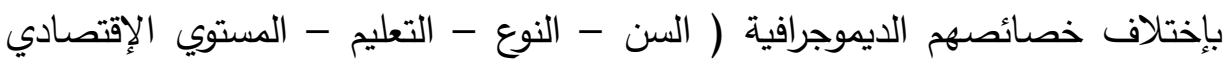

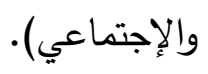

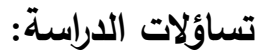

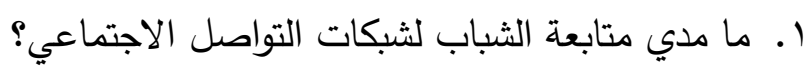
r. ما مدي اعتماد الثباب علي شبكات التواصل الاجتماعي لتشكيل اتجاهتهم نحو

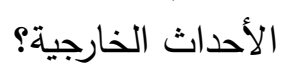

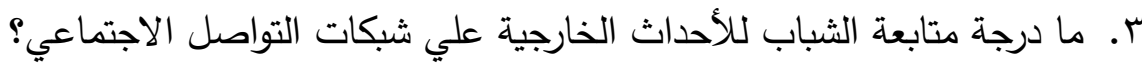

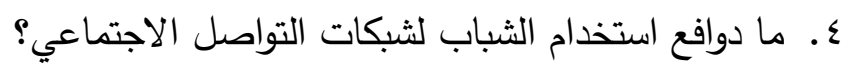

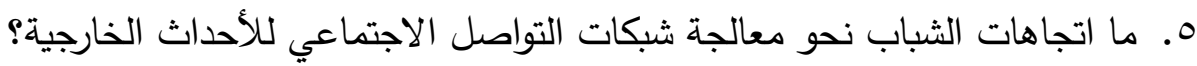

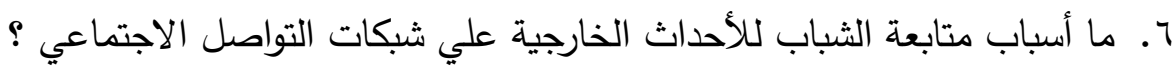

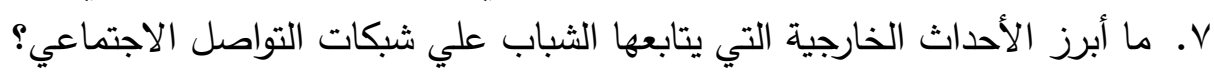

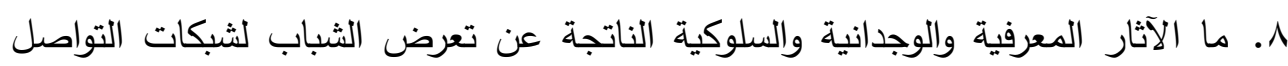

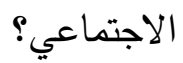

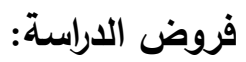

تسعي الدراسة إلي التأكد من صحة الفروض الآتيه:

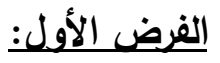


توجد علاقة ارتباطية دالة إحصائية بين معدل التعرض لثانية لثبكات التواصل الاجتماعي واتجاهات الثباب نحو الأحداث الخارجية. الفرض الثاني: - (اتجاهات الكياب توجد علاقة ارتباطية دالة إحصائياً بين درجة الاعتماد علي شبكات التواصل الاجتماعي

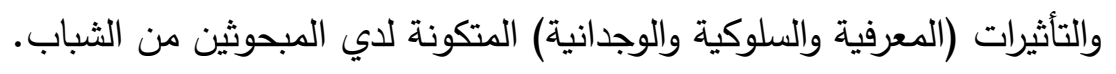

|لفرض الثالث:

توجد فروق ذات دلالة احصائية بين اتجاهات الثباب نحو معالجة شبكات التواصل

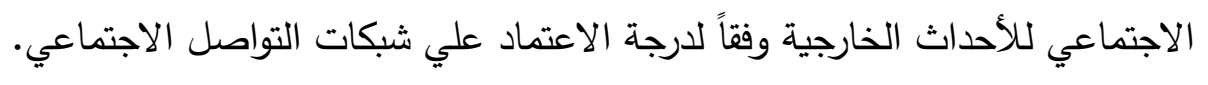

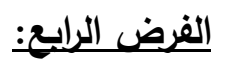
توجد فروق دالة إحصائية بين اتجاهات الثباب نحو معالجة شبكات التواصل الاجتماعي

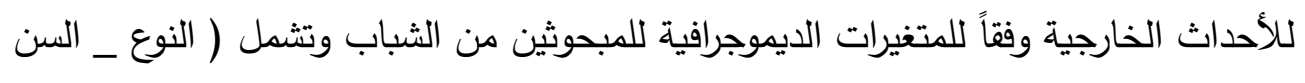

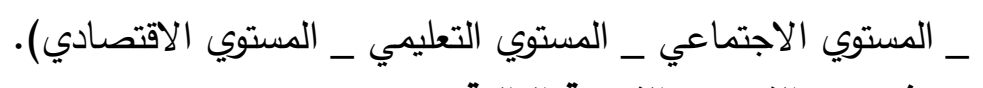
وينبثق منه الفروض الفرعية التالية:

أ- - هناك فروق ذات دلالة إحصائية بين اتجاهات الثباب نحو معالجة شبكات التواصل الاجتماعي للأحداث الخارجية وفقاً للنوع.

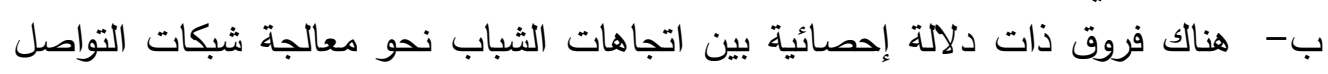
الاجتماعي للأحداث الخارجية وفقاً للسن.

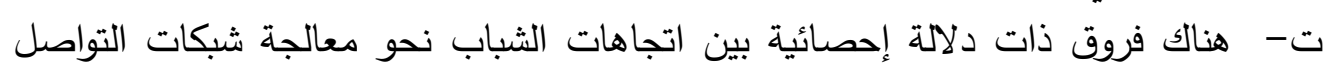

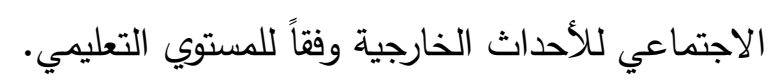

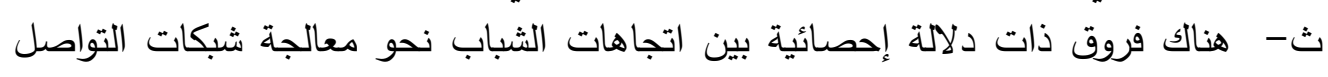

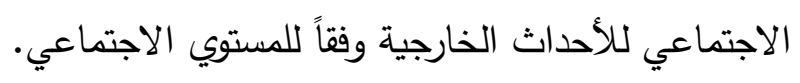

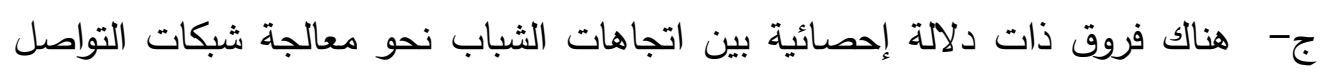
الاجتماعي للأحداث الخارجية وفقاً للمستوي الاقتصادي.

\section{|لفرض الخامس:}

هناك فروق ذات دلالة إحصائية بين درجة الاعتماد علي شبكات التواصل الاجتماعي في الإني

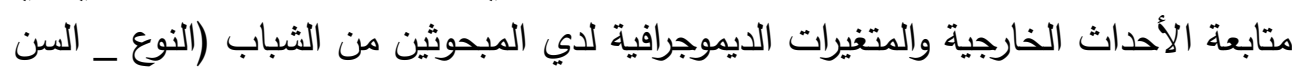
_ المستوي الاقتصادي _ المستوي الاجتماعي _ المستوي التعليمي). 
دور شبكات التواصل الاجتماعي في تثكيل اتجاهات الثباب

وينبثق منه الفروض الفرعية التالية:

أ- هنالك فروق ذات دلالة إحصائية بين درجة الاعتماد علي شبكات التواصل الإنه الاجتماعي في متابعة الأحداث الخارجية لدي المبحوثين من الشباب وفقاً للنوع.

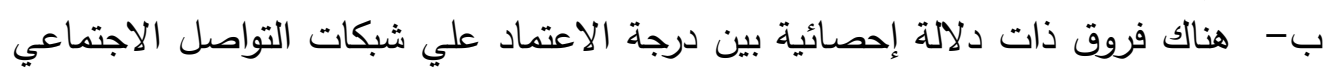

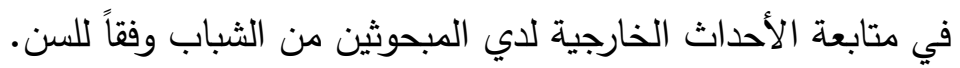

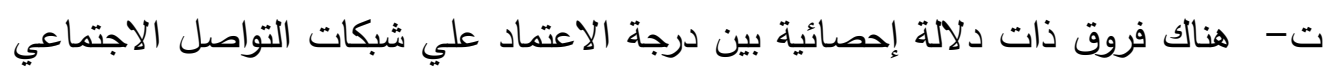
في متابعة الأحداث الخارجية لدي المبحوثين من الثباب وفقاً للمستوي الاقتصادي.

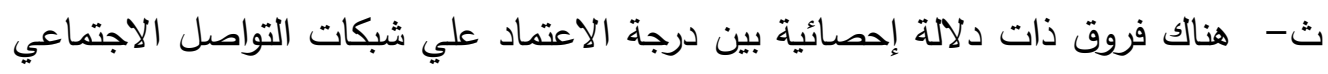

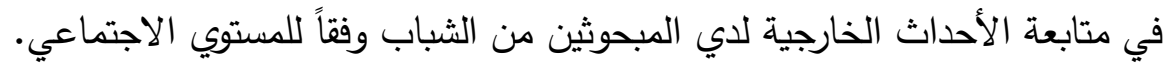

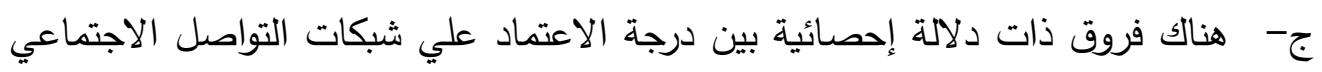

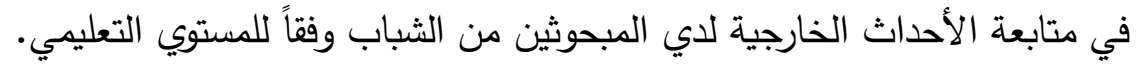

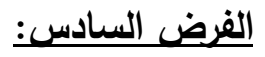
توجد علاقة ارتباطية ذات دلالة إحصائية بين دوافع متابعة الشباب للأحداث الخارجية عبر شبكات التواصل الاجتماعي واتجاهاتهم نحوها. الفصل الثاني: الدور الإخباري والإعلامي لشبكات واتهات التوهاصل التهل الاجتماعي. تمهيد: لقد أصبح الأنترنت مصدراً رئيسياً للأخبار بالنسبة للأشخاص، في البلدان التي تتوفر فيها هذه الأخبار والتي يمكن الوصول إليها.

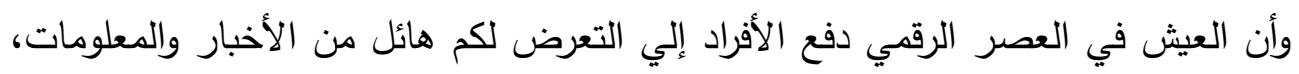

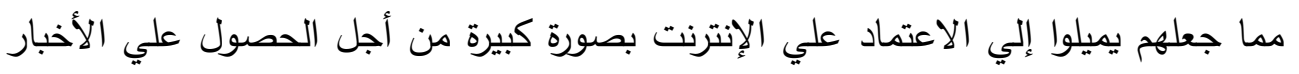

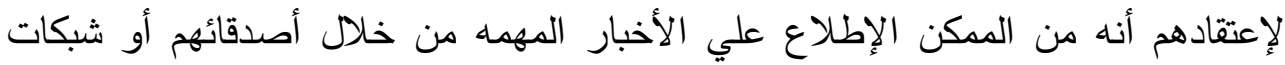

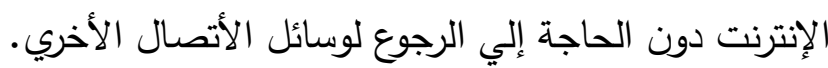

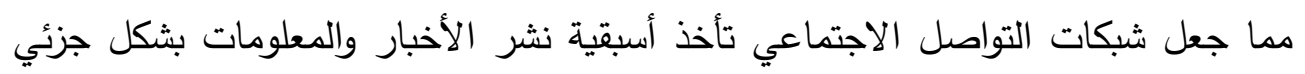

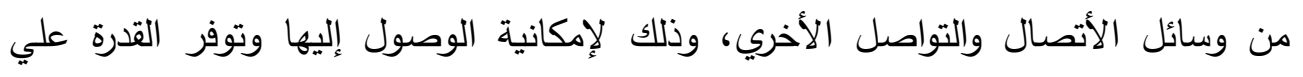
استخدامها، وبذلك يتزايد إقبال الجماهير علي استخدام شبكات التواصل الاجتماعي لشعورهم بأنها مجدية بالنسبة لهم بشكل أفضل من أشكال الاتصال الأخري، وأن شبكات التوات التواصل

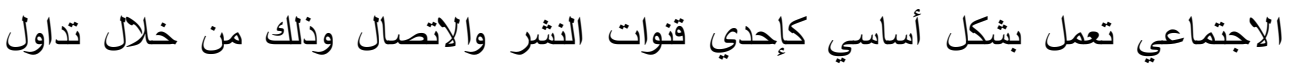
الأخبار والمعلومات من خلآلها. 


\section{الباحثة/أسماء عبده زكي المرزوقي}

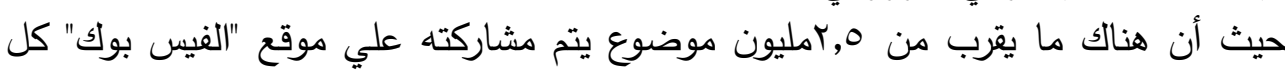

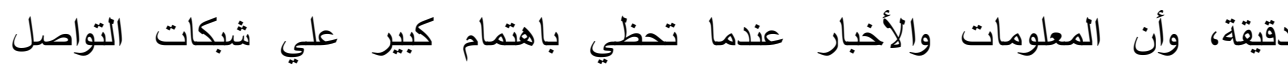

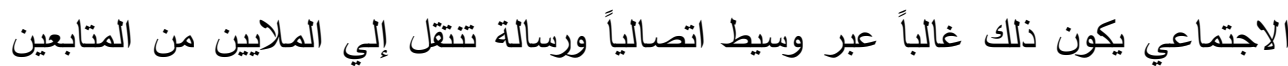

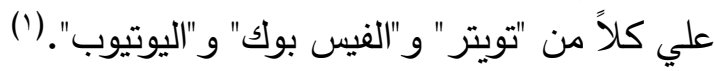

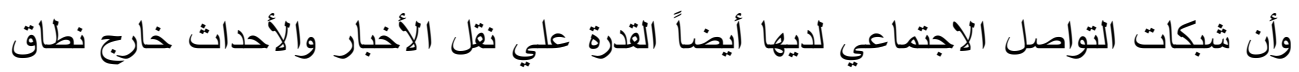

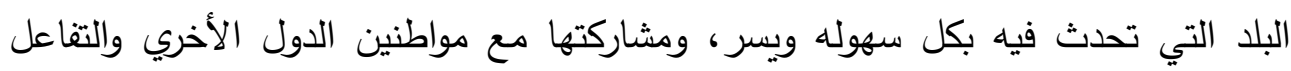

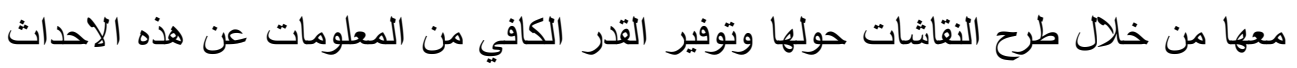

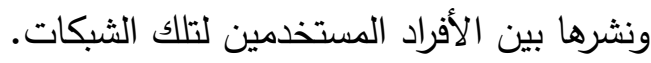

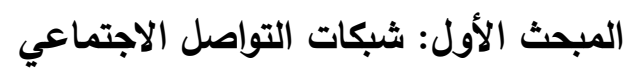
تعريف شبكات التواصل الاجتماعي:

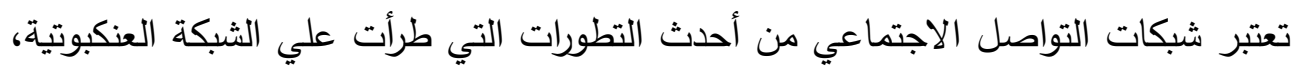

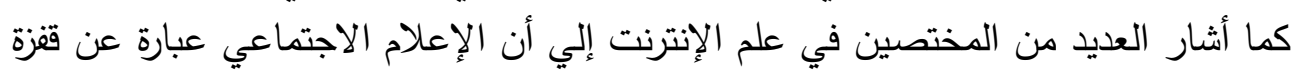

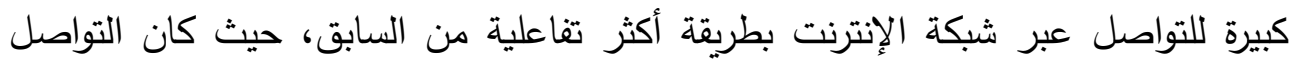

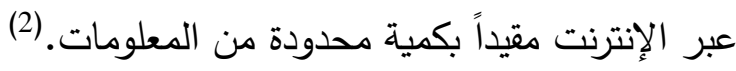

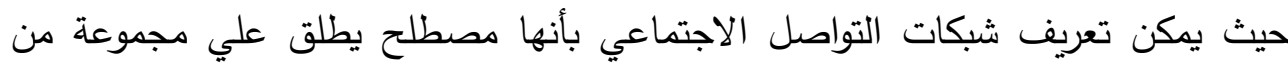

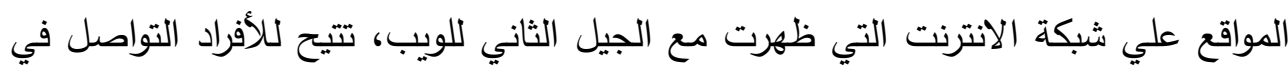

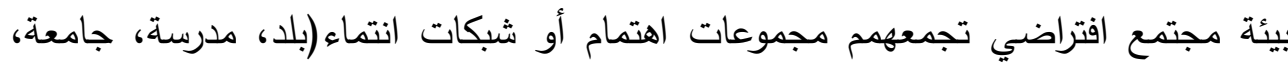

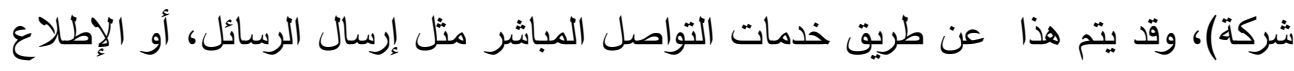

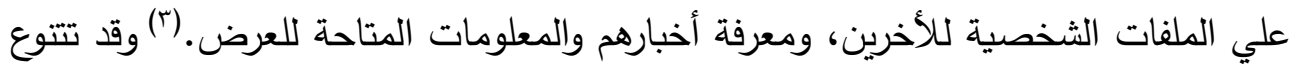

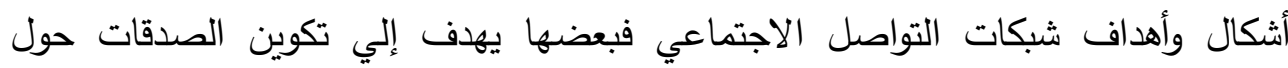
العالم، ويهدف البعض الآخر إلي تكوين شبكات اجتماعية في مجال محدد (مثل شبكات الإنيات

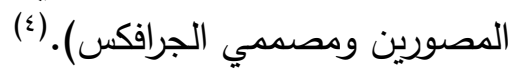

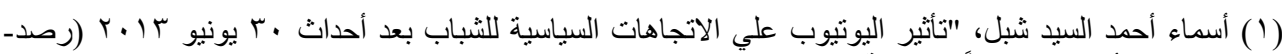

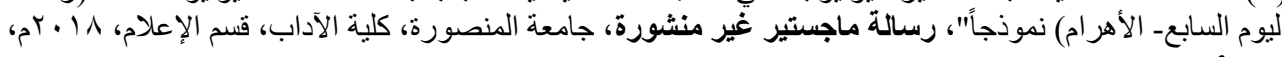

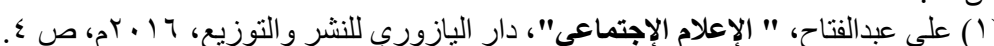

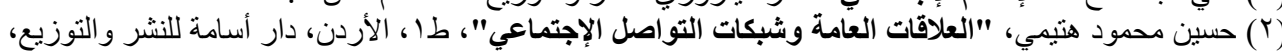


دور شبكات التواصل الاجتماعي في تشكيل اتجاهات الثباب

وعرف إليسون وبويد "Ellison \& Boyed" شبكات التواصل الاجتماعي بأنها خدمات عبر الاجتي

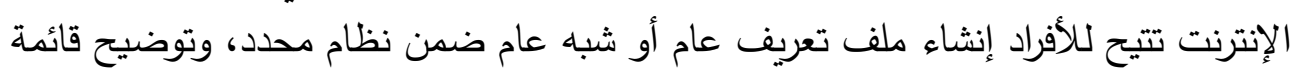

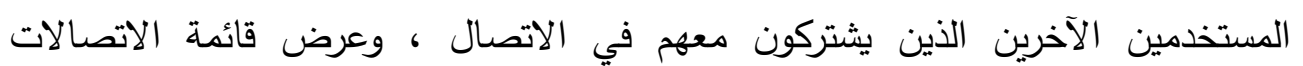

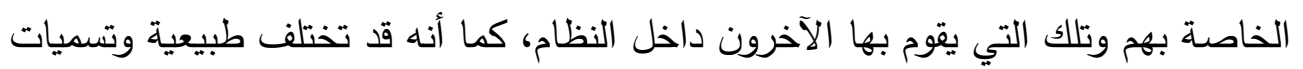

هذه الاتصالات من موقع إلي آخر .(')

خصائص شبكات التواصل الاجتماعي:

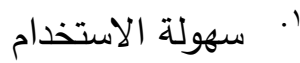

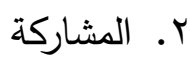

r. ب. التفاعلية

ـ. المجموعات

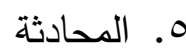

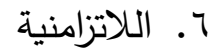

v. ألبومات الصور

^. التعريف بالذات

9 9. وسائل الإعلام البديلة

أنواع شبكات التواصل الاجتماعي:

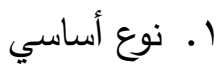

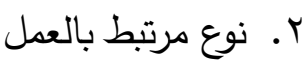

r. نوع به مميزات إضافية

ع. الشبكات العربية

ه. المواقع الاجتماعية والأعمال

مستخدمي شبكات التواصل الاجتماعي:(r)

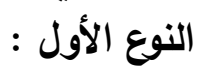

(๕) Roger Edwards, " Benefits of social networking websites for young people", GRIN Verlag, 2014, p.4 .

(1) إسراء محمد إبراهيم قميحة، "تأثير تعرض الثباب الجامعي للأخبار السلبية علي مواقع التواصل الاجتماعي

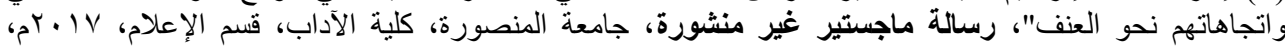


تتمثل في فئة الثباب عبده زكي المرزوقين أبي أصحاب الثهادات، وخريجي الجامعات والفئات الثبابية

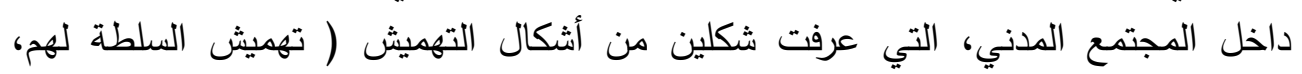
وتهميش المجتمع المدني)، والتي تجد نفسها في مفترق الطريق، كما أصبحت شبكات

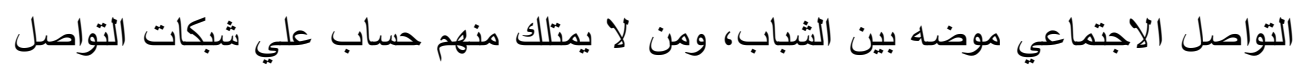

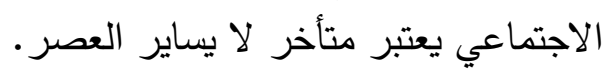
النوع الثاني : الاجئي يتمثل في فئة النخب، سواء كانت تتنمي لأحزاب سياسية، أم لمنظمات المجتمع المدني، أو

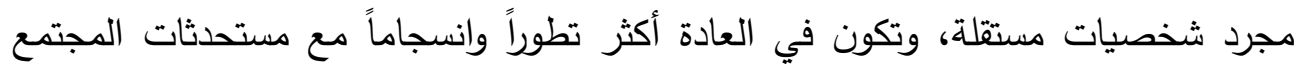
الذي يعيشون فيه، نظراً لامتلاكها للزاد المعرفي والمستوي التعليمي والموقع الاجتماعي المتميز .

كما يمكن تقسيم مستخدمي شبكات التواصل الاجتماعي إلي ما يلي ('):

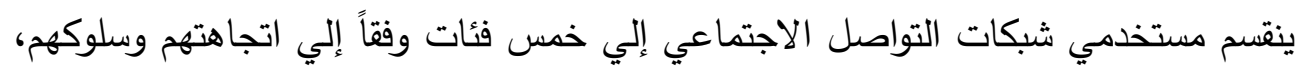
حيث تختلف اتجاهات المستخدمين نحو تلك الثبكات وسلوكهم حين استخدامها: 1. الاجتماعيون القادة (Alpha Socialisers): وهم قلة تستخدم شبكات التواصل الاجتماعي بصورة مكثفة لفترة قصيرة من أجل الترفية والتعرف علي أشخاص آخدمن آخرين.

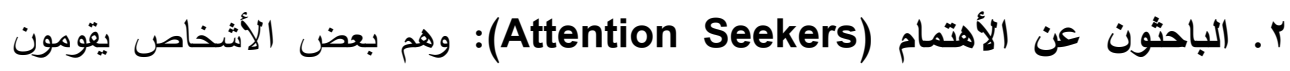
بوضع الصور وتتظيم صفحاتهم الثخصية لجذب اهتمام الآخرين. r. المتابعون (Followers): هم كثيرون انضموا إلي شبكات التواصل الاجتماعي تقليداً لقرنائهم. צ. المخلصون (Faithfuls): هم كثيرون يستخدمون شبكات التواصل الاجتماعي من أجل إحياء صداقات قديمة من المدرسة والجامعة. ه. الوظيفيون (Functionals): وهم قلة تستخدم شبكات التواصل الاجتماعي لغرض ولجه محدد. المبحث الثاني: مصداقية شبكات التواصل الاجتماعي كمصدر للأخبار والأحداث المختلفة

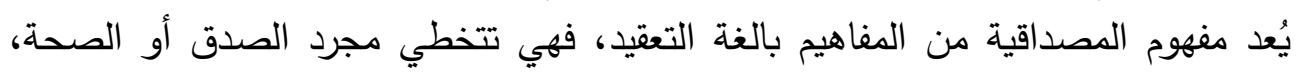

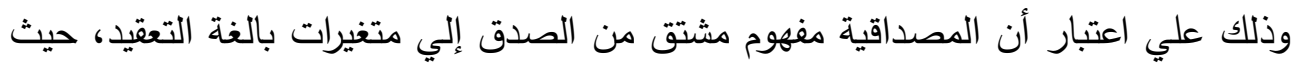

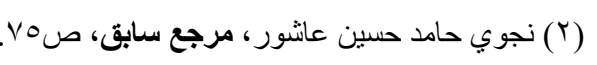

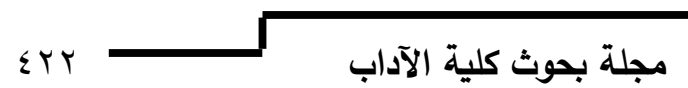


دور شبكات التو اصل الاجتماعي في تثكيل اتجاهات الثباب

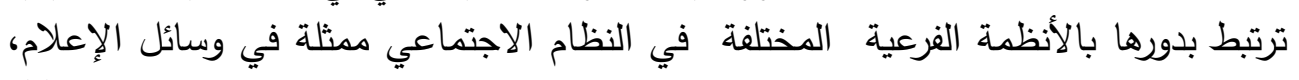

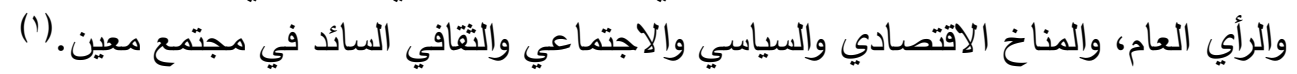
ويمكن تعريف المصداقية بأنها "قابلية الجمهور لتصديق المحتوي الاتصالي استتاداً إلي أحد

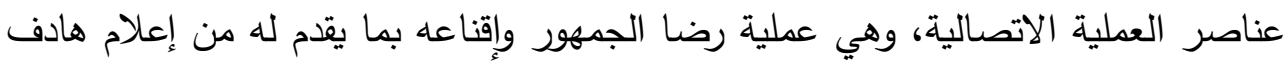

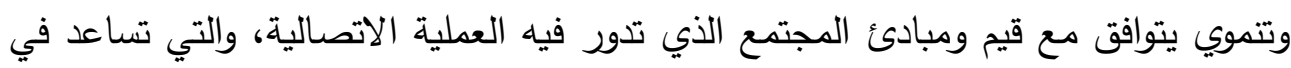

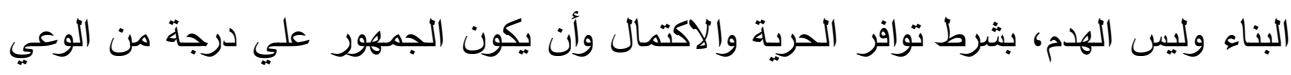

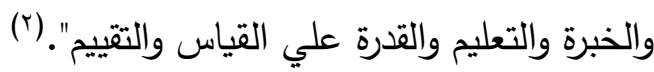

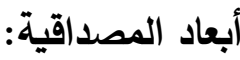
يمكن تحديد أبعاد المصداقية: المداد فيما يلي:

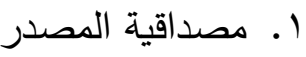

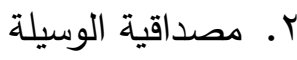

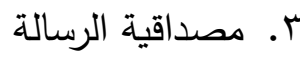
مستويات المصداقية: مئل

صمح (Wolfgang Schweiger) نموذج بنائي هرمي الثكل يُمثل مستويات مصداقية

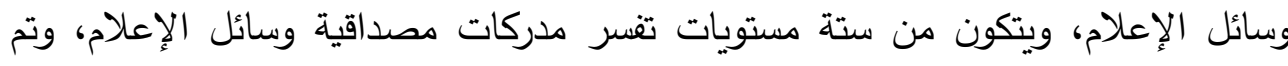

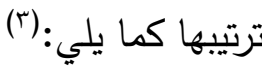

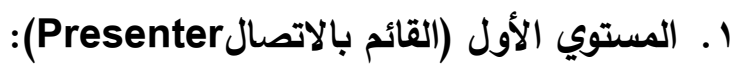

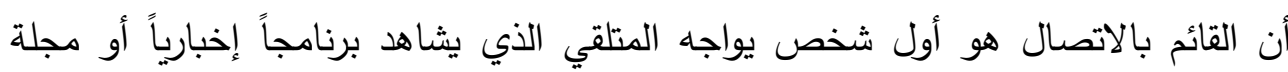
سياسية علي التليفزيون، ويمكن للمستقبل تقييم درجة مصداقية القائم بالاتصال، وأن القائم بالاتصال بمفهومه الأوسع هو مذيع في التليفزيون أو الكاتب في صحيفة أو في صفي صنحات الويب.

r. المستوي الثاني ( مصدر الحدث Actor-Source): هو التقرير الإخباري لأفعال أو تصريحات بعض الأشخاص المعنيين والمسؤلين مثل الشخصيات السياسية.

و (1) شيرين محمد كدواني، "مصداقية الإتترنت..العو امل المؤثرة ومعايير التقييم"، طا، القاهرة، دار العربي للنشر

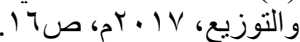

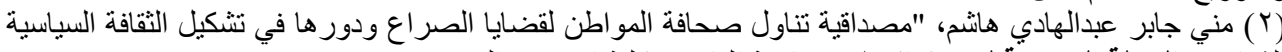

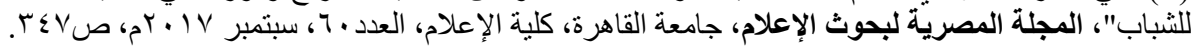
(3) Wolfgang Schweiger, Op.Cit, p.39-41.

مجلة بحوث كلية الآداب 
الباحثة/أسماء عبده زكي المرزوقي

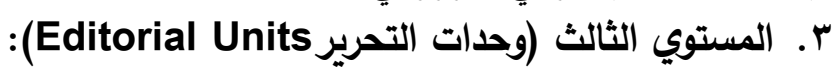

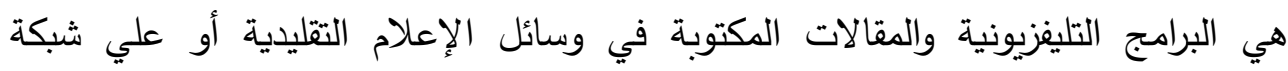

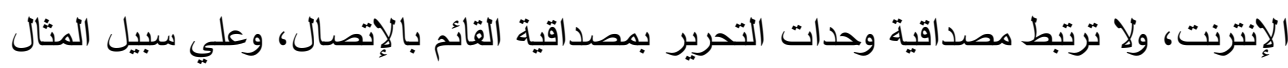

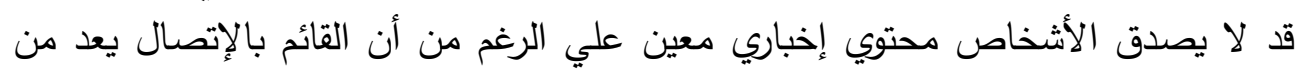
الثخصيات الموثوق بها. ؛. المستوي الرابع (المنتج الإعلامي Media Product):

قد ينسب المستقبل المصداقية إلي علامات تجارية مشهورة أو شبكات تليفزيونية معروفة. ه. المستوي الخامس (المنتج الإعلامي الفرعي Single Media Product)

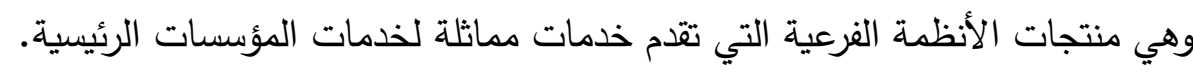

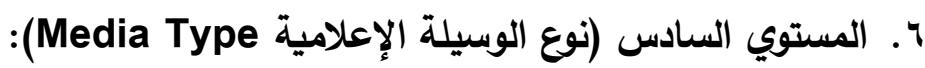

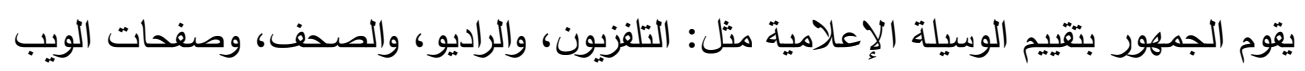
بثكل كامل. النتائج العامة للدراسة: توصلت الاراسة إلي مجموعة من النتائج أبرزها:

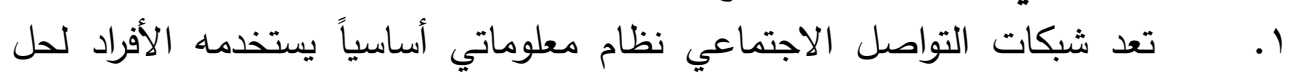

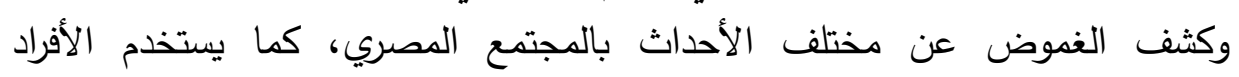

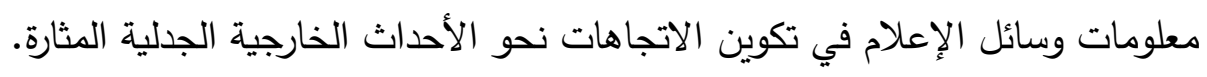

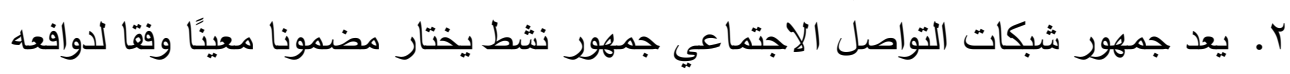
وحاجاته. r. أكدت النتائج ارتفاع المعدل اليومي لاستخدام شبكات التواصل الاجتماعي وكثافة

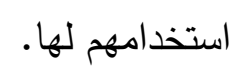

ء. أوضحت النتائج ارتفاع نسبة الوقت الذي يقضيه المبحوثين أثناء التصفح في شبكات

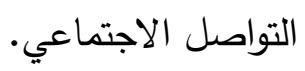

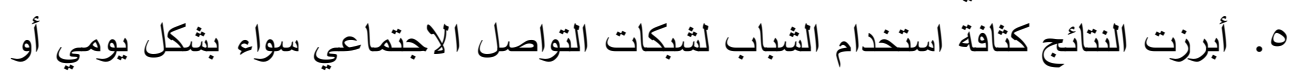

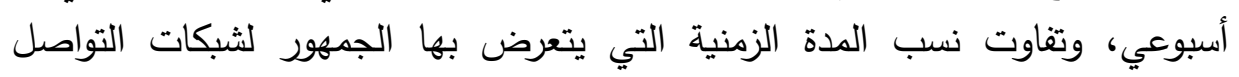

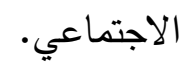




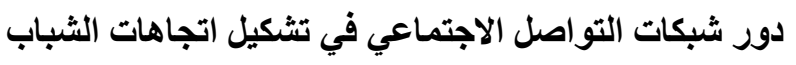

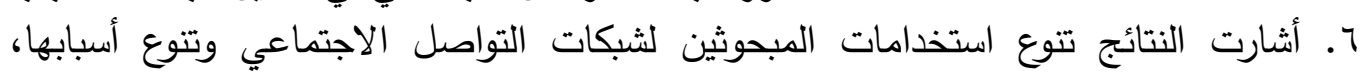
وأهمية شبكات التواصل الاجتماعي لدى المبحوثين.

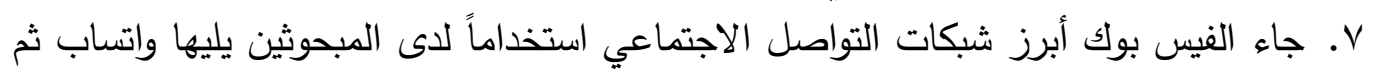

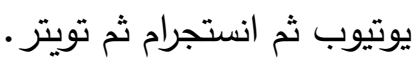

^. كانت الأحداث السياسية الأبرز متابعة يليها الأحداث الاجتماعية ثم الدينية ولكن بمعدل متوسط، ومستوى اعتمادية متوسطة لتشكيل اتجاهات المبحوثين نحو الأحداث الخارجية، وأن مستوى الثقة متوسط. 9 ـ. أبرزت الدراسة كثافة اشتراك المبحوثين على مواقع شبكات التواصل الاجتماعي المهتمة بمتابعة الأحداث الخارجية، وفاعلية مواقع التواصل الاجتماعي في المشاركة في الأحداث

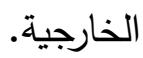
• أوضحت النتائج قوة أسباب تعرض الجمهور لشبكات التواصل الاجتماعي، جاءت أبرز أسباب متابعة الأحداث الخارجية علي شبكات التواصل الاجتماعي، التعرف علي الأحداث

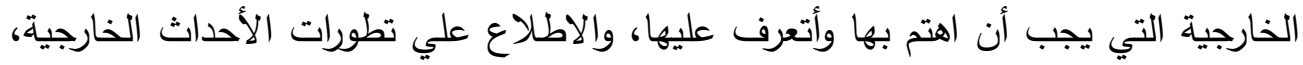

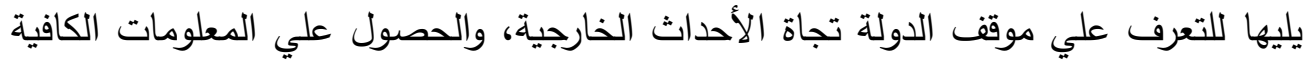

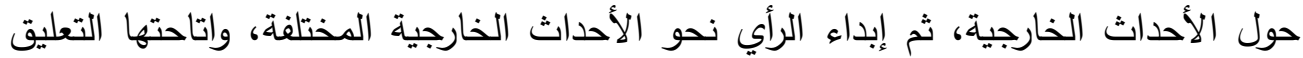

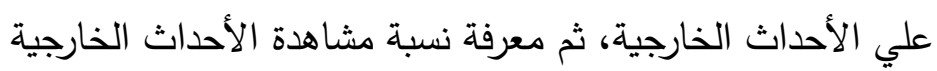
11 ا.جاءت قضية سد النهضة القضية الأبرز متابعة لدى المبحوثين عينة الدراسة نظرًا لارتباطها

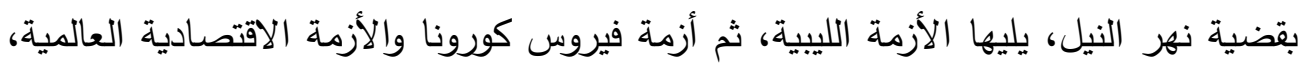
والاحتجاجات بأمريكا ضد العنصرية، وفي الترتيب الرابع كانت أزمة المسلمين الايغورين،

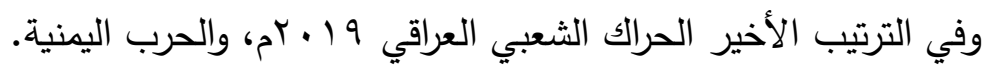

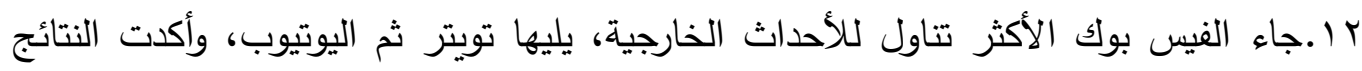

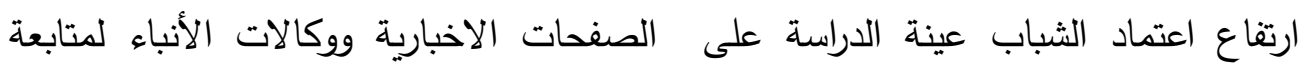
الأحداث الخارجية، وأن مستوى استفادة الثباب بتلك المعلومات متوسطة.

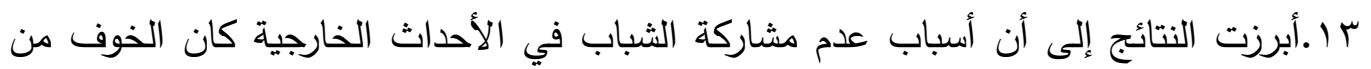

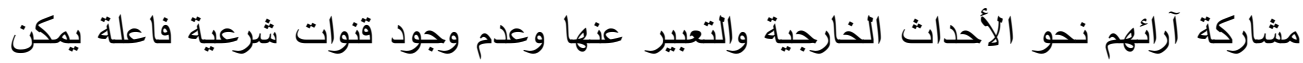

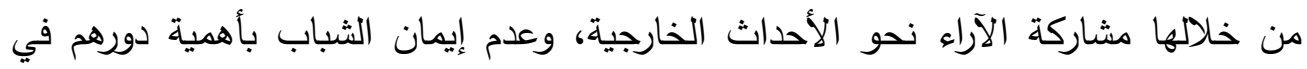
المشاركة بآرائهم نحو الأحداث الخارجية. 
الباحثة/أسماء عبده زكي المرزوقي

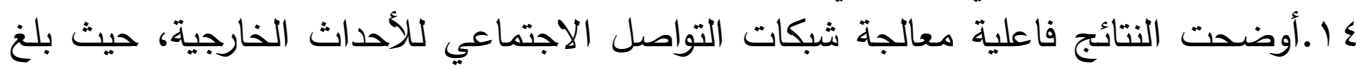

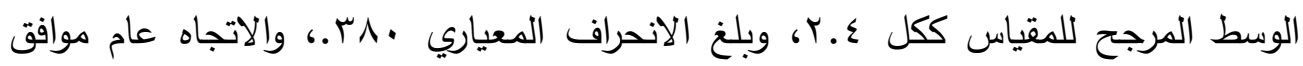

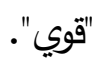

10 ا.قوة الاستفادة المعرفية المتحققة والناتجة من التعرض لثبكات التواصل الاجتماعي في متابعة الإنا

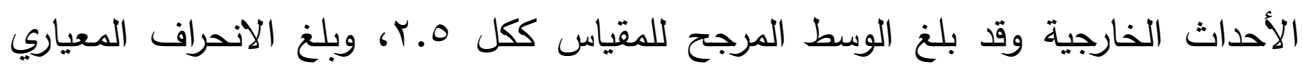

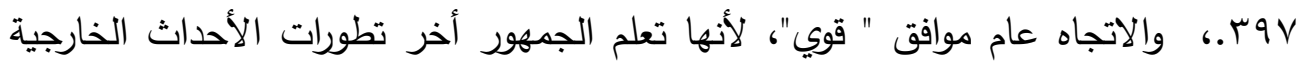

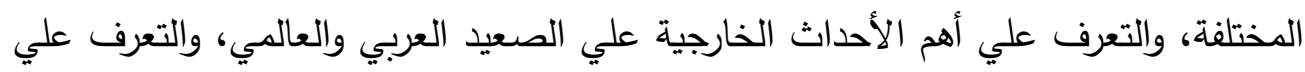

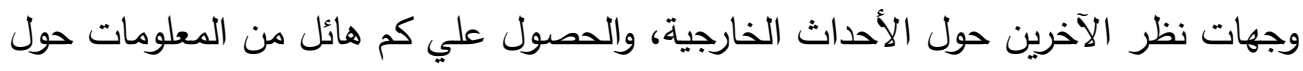

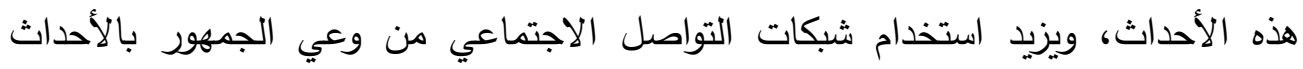

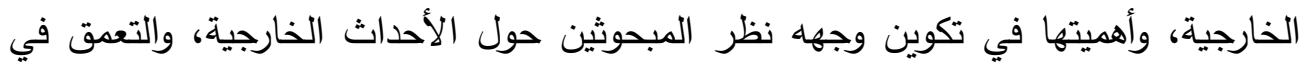

$$
\text { معرفة وجهات نظر المسؤولين حول الأحداث الخارجية. }
$$

17 أشنارت النتائج أن الأثار الوجدانية كانت متوسطة لألى الأى الثباب عينة الدراسة، وقوة الاستفادة

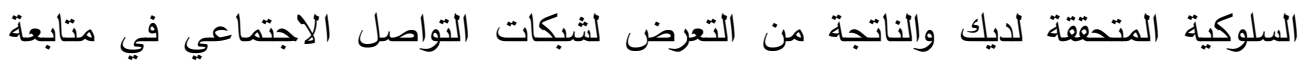

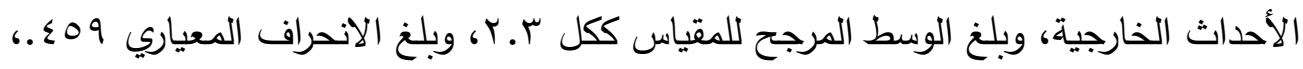

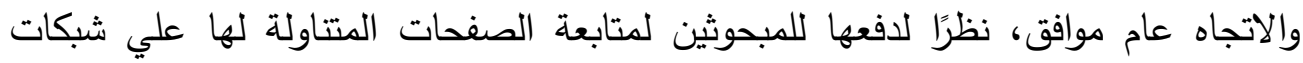

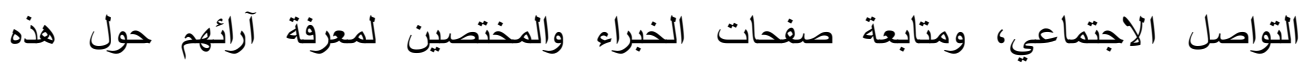

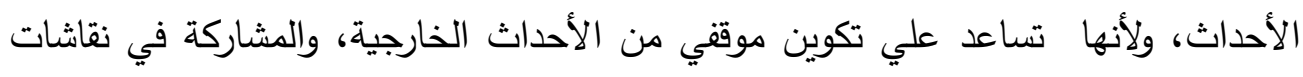

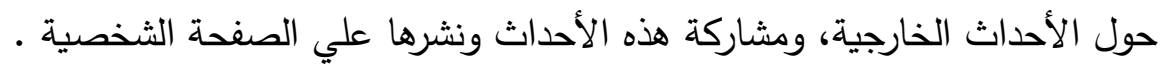

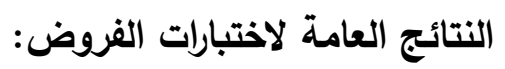

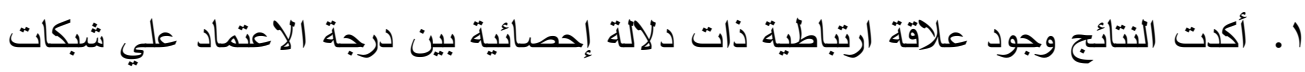

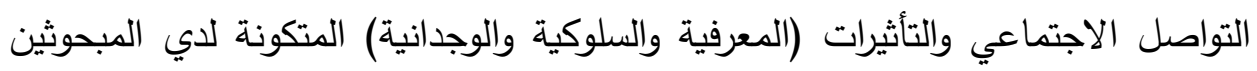

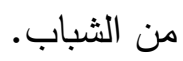
r. أثارت النتائج عدم صحة الفرض القائل بوجود علاقة ارتباطية ذات دلالة إحصائية بين

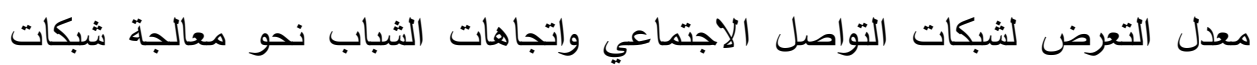
التواصل الاجتماعي للأحداث الخارجية ل التبن 


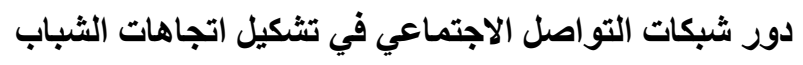

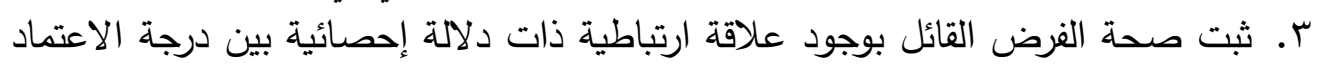

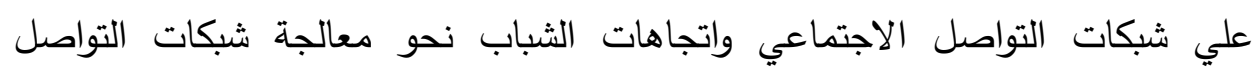
الاجتماعي للأحداث الخارجية.

ع. عدم صحة الفرض القائل بأن هناك فروق ذاعة الات دلالة إحصائية بين درجة الاعتماد علي شبكات التواصل الاجتماعي وفقا للنوع.

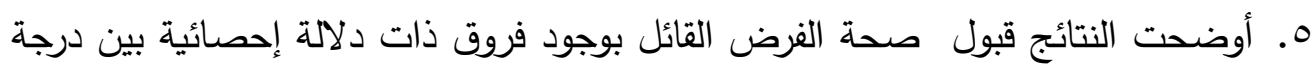

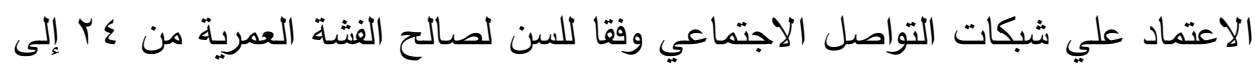

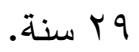

I. عدم صحة الفرض القائل بوجود فروق ذات دلالة إحصائية بين درجة الاعتماد علي شبكات التواصل الاجتماعي وفقا للمستوى الاقتصادي.

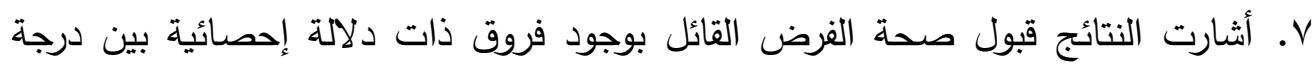

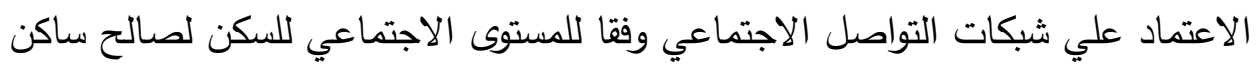
في شقة بحي شعبي. ^. أكدت النتائج عدم صحة الفرض القائل بوائل بوجود فروق ذات دلالة إحصائية بين درجة الاعتماد علي شبكات التواصل الاجتماعي وفقا للمستوى التعليمي.

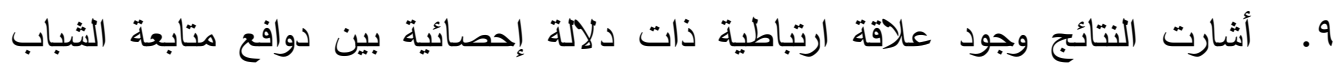

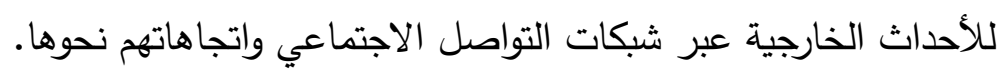

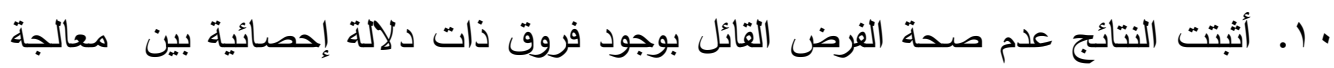

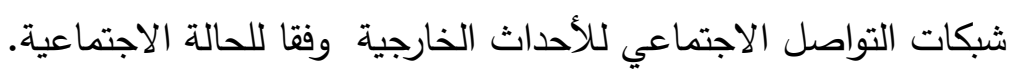

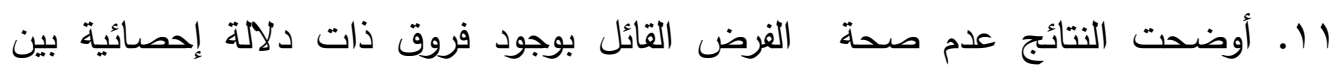

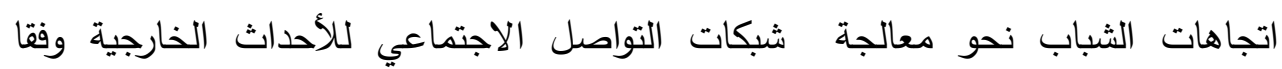

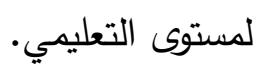
r أ. أكدت النتائج وجود فروق ذات دلالة إحصائية بين اتجاهات الثباب نحو معالجة شبكات

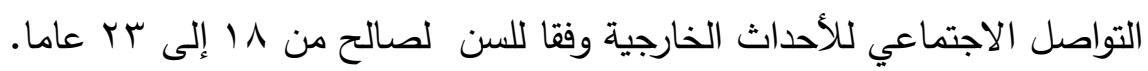

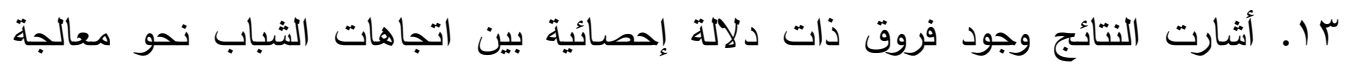

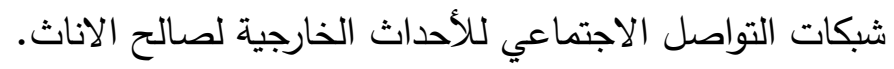

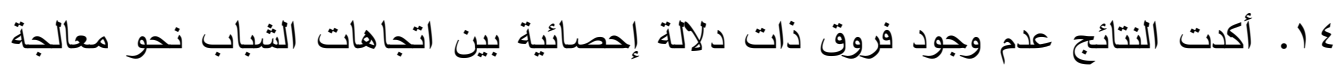
شبكات التواصل الاجتماعي للأحداث الخارجية وفقاً للمستوي الاقتصادي. بلادي. 


$$
\text { الباحثة/أسماء عبده زكي المرزوقي }
$$

10. أثبتت النتائج وجود فروق ذات دلاتلاتلة إحصائية بين اتجاهات الثباب نحو معالجة شبكات

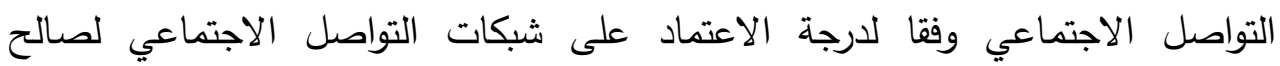

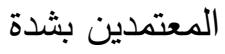

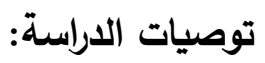
توصي الدراسة بمجموعة من المبادئ والأسس في إطار توظيف شبكات التواصل الاجتماعي الجديد واعتماد الجمهور عليها في تثكيل معارفهم واتجاهاتهم نحو الأحداث

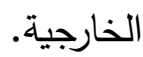

$$
\text { والتي جاءت على النحو الاتي: الإني: }
$$

ا. النظر إلى الإنترنت باعتباره وسيلة إعلامية مؤثرة، وتلعب دورا رئيساً في تغيير اتجاهات وسلوكيات الجمهور نحو بعض الظواهر ، ولاسيما الحشد نحو الأحداث الخارجية على شبكة الإنيكة الإتترنت، والعمل على استثمار شبكات التواصل الاجتماعي، والاستفادة من خدماتها في

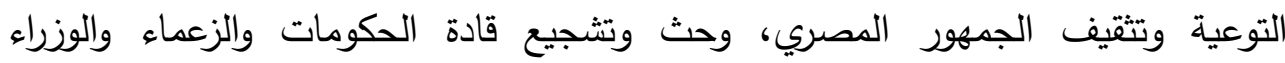

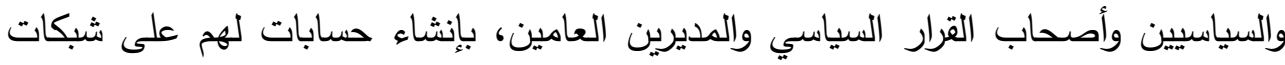

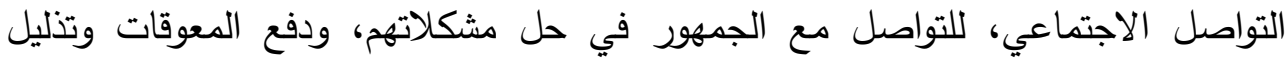

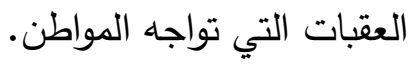

r. إخضاع الثبكات الاجتماعية لمزيد من الدراسات المتعمقة التحليلية والميدانية؛ للاستفادة

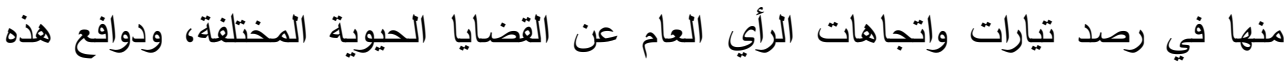

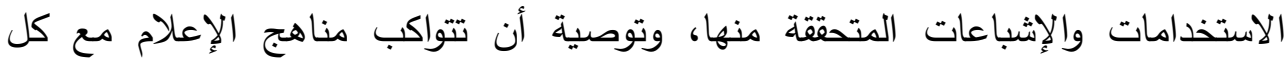

$$
\text { المستحدثات في هذا الموضوع. }
$$

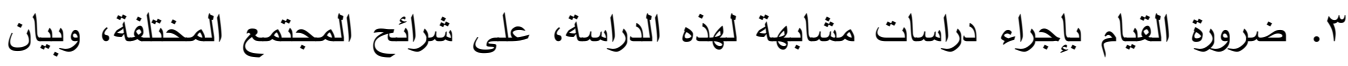

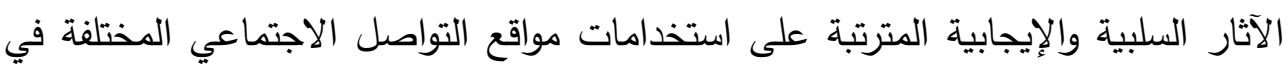

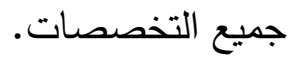

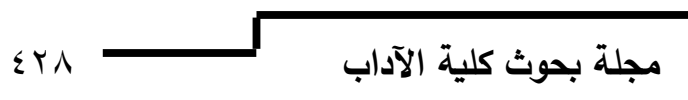

